\title{
MULTI-OBJECTIVE ECONOMIC PRODUCTION QUANTITY MODEL FOR FULLY BACKLOGGED PROBLEM WHERE DEMAND DEPEND ON SOME CONDITIONS AND PERMISSIBLE DELAY IN PAYMENT
}

\author{
Abhishek Kanti Biswas \\ R. K. M. Vivekananda Centenary College, India \\ E-mail: a.k.biswas@hotmail.com \\ Sahidul Islam \\ University of Kalyani, India \\ E-mail: sahidul.math@gmail.com
}

Submission: 04/09/2018

Revision: 18/09/2018 Accept: 15/10/2018

\section{ABSTRACT}

For any business, the inventory system takes a monumental part. Keep this aspect in mind, we formulate multi-objective displayed $E P Q$ model consider with non-instantaneous deteriorating items where production depends on demand and variable demand pattern depends on display shelf-space, selling price and frequency of advertisement of the items. The customers are more attracted to buy an item by observing display shelf-space, selling price and advertisement. For any inventory system, defective and deteriorated items are now and again come back to providers for a discount or credit. Here price discount is available for deteriorated and defective items. Holding cost varies with time where shortages are allowed and fully backlogged. Delay in payment is permissible. Fuzzy environment touches the reality instead of the crisp environment. So, we assumed the cost components (parameters) as Linear Fuzzy Numbers and then using Nearest Interval Approximation Method the parameters converted to parametric interim -valued function for solving the model in a fuzzy environment. Finally, several numerical examples are given to illustrate the model. Also graphs are given for the optimal 
values of $t_{2}^{*}, t_{3}^{*}$ and $\operatorname{Tac}\left(t_{2}^{*}, t_{3}^{*}\right)^{*}$ corresponds to change the value of $v \in[0,1]$.

Keywords: EPQ inventory, Demand dependent production, Fully backlogged, Triangular Fuzzy Numbers, Nearest Interval Approximation Method.

\section{INTRODUCTION}

To controlling any business, Inventory analysis is an important part. Analysts around there have broadened examination concerning different inventory models with contemplations of demand designs, deterioration, deficiencies, payment options, arrange cycles and their combinations. Economic Production Quantity Inventory Model requires watchful and mindful methodology.

By controlling quality, manufacturers ordinarily need to deliver the perfect volume of items. In the current years, the deteriorating items have gotten much consideration in light of the fact that the vast majority of the physical merchandise experience decay or deterioration after lifetime, a case being natural products, vegetables, unstable products et cetera.

In such circumstance price discount are normal practices by a provider to encourage the client to buy a considerable measure estimate or defective items other than standard buy. In 1963, the first attempt at the analysis of the deteriorating inventory model was made by Ghare and Schrader (1963) with a constant rate of decay.

Wee (1999) developed a deteriorating inventory model with a quantity discount, pricing, and partial back ordering. Connecting above, Ouyang et. al. (2006), researched an inventory model for non-instantaneous deteriorating items with the permissible delay in payments. Holding costs are one component of total inventory costs that are associated with storing inventory that remains unsold. Also, Demand is different for different types of item, item quality, customers of the certain area, selling price, advertisement of the items and different period of time.

According to retailers' reputation and quality of items, in some inventory system, customers are waiting for the next replenishment. So, fully backlogged is acceptable. Mondal and Islam (2016), examined a fuzzy EOQ display for deteriorating things, with constant demand, shortages and fully backlogging. While modelling an inventory 
INDEPENDENT JOURNAL OF MANAGEMENT \& PRODUCTION (IJM\&P)

http://www.ijmp.jor.br

v. 10, n. 3, May - June 2019

ISSN: 2236-269X

DOI: 10.14807/ijmp.v10i3.865

problem, display inventory level demands have an effect on sales for many retail products.

According to Whitin (1957), "For retail stores, the inventory control problem for style goods is further complicated with the fact that inventory and sales are not independent of one another. An increase in inventory may bring about increased sales of some items". In the present competitive market, the effect of marketing policies and conditions such as the price variations and the advertisement of an item change its demand pattern amongst the public.

Very few OR researchers and practitioners studied the effects of price variations and the advertisement on the demand rate for items. Ladany and Sternleib (1974) studied the effect of price variation on selling and consequently on EOQ. Nonetheless, they didn't think about the impact of the advertisement. Subramanyam and Kumaraswamy (1981) and Urban (1992), created inventory models consolidating the impacts of selling price an advertisement of a thing. Sometimes, the supplier will offer the retailer a trade credit period in a competitive market environment, in paying for the amount of purchasing cost.

Usually, if the retailer sells the whole items inside the cut-off period and settled the outstanding amount within the permitted fixed settlement period there is no charge. If the settled pay date passes, interest is changed by a supplier for the rest of the products that are in stock. Numerous specialists have thought about the aforesaid condition in various ways. Ou (2016), built up a model of an optimal replenishment policy under Conditions of permissible delay in payment.

Applying the conventional inventory model as they are generally, leads to erroneous decisions, are not capable of representing real-life situations. Fuzzy inventory models fulfil that gap. Different fuzzy inventory models occur due to fuzzy various cost parameters in the total cost. Fuzzy set theory, introduced by Zadeh (1965), has been receiving considerable attention from researchers in production and inventory management as well as in other fields.

Zadeh and Bellmann (1970) proposed a mathematical model for basic leadership in a fuzzy domain. Dubois and Prade (1978) characterizes a few activities on fuzzy numbers. Zimmermann (1985) made an attempt to use the fuzzy sets in operation research. Grzegorzewski (2002) investigate the nearest interval 
INDEPENDENT JOURNAL OF MANAGEMENT \& PRODUCTION (IJM\&P)

http://www.ijmp.jor.br

v. 10, n. 3, May - June 2019

ISSN: 2236-269X

DOI: 10.14807/ijmp.v10i3.865

approximation of a fuzzy number. Mondal and Roy (2006), approximated Linear Fuzzy Number in a fuzzy environment.

In the present work, we developed a multi-objective fuzzy deterministic inventory model for non-instantaneous deteriorating items where demand depends on display shelf-space, selling price and advertisement. Holding cost is expressed as the function of time. Shortages are allowed and fully backlogged. The inventory costs are taken as Linear Fuzzy Number. Using Nearest Interval Approximation Method, the parameters converted to parametric interim -valued function for solving the model in a fuzzy environment. The solution for minimizing the total cost has been derived. To the author's best of knowledge such type of model has not yet been discussed in the inventory literature.

\section{DEFINITIONS AND FUZZY PRELIMINARIES}

For this model, we need the following definitions:

- Definition 2.1: A fuzzy set $\widetilde{A}$ is a universe of discourse $X$ is defined as the following set of pairs $\widetilde{A}=\left\{\left(x, \mu_{\tilde{A}}(x): x \in X\right\}\right.$. Where $\mu_{\tilde{A}}(x) \rightarrow[0,1]$ is a mapping called the membership function of the set $\widetilde{A}$ and $\mu_{\tilde{A}}(x)$ is called the membership value or degree of membership of $x \in X$ in the fuzzy set $\widetilde{A}$. The larger $\mu_{\tilde{A}}(x)$ is stronger the grade of membership form in $\widetilde{A}$.

- Definition 2.2: A fuzzy set $\tilde{A}$ of the universe of discourse $X$ is convex if and only if for all $x_{1}, x_{2} \in X, \mu_{\tilde{A}}\left(\lambda x_{1}+(1-\lambda) x_{2}\right) \geq \min \left[\mu_{\tilde{A}}\left(x_{1}\right), \mu_{\tilde{A}}\left(x_{2}\right)\right]$ when $0 \leq \lambda \leq$ 1.

- Definition 2.3: A fuzzy set $\widetilde{A}$ of the universe of discourse $X$ is called normal fuzzy set implying that there exists at least one $x \in X$ such that $\mu_{\tilde{A}}(x)=1$.

- Definition 2.4: The $\alpha$-cut of $\widetilde{A}$ is defined as a crisp set $A_{\alpha}=\left\{\mathrm{x}: \mu_{\tilde{A}}(\mathrm{x}) \geq \alpha\right.$, $x \in X$ where $\alpha \in[0,1] . A_{\alpha}$ is a non-empty bounded closed interval contained in $X$ and it can be denoted by $A_{\alpha}=\left[A_{L}(\alpha), A_{R}(\alpha)\right]$. Where $A_{L}(\alpha)$ and $A_{R}(\alpha)$ are the lower and upper bounds of the closed interval respectively.

- Definition 2.5: A fuzzy number is a fuzzy set in the universe of discourse $X$ that is both convex and normal. The following figure 1 shows a fuzzy number $\widetilde{A}$. 


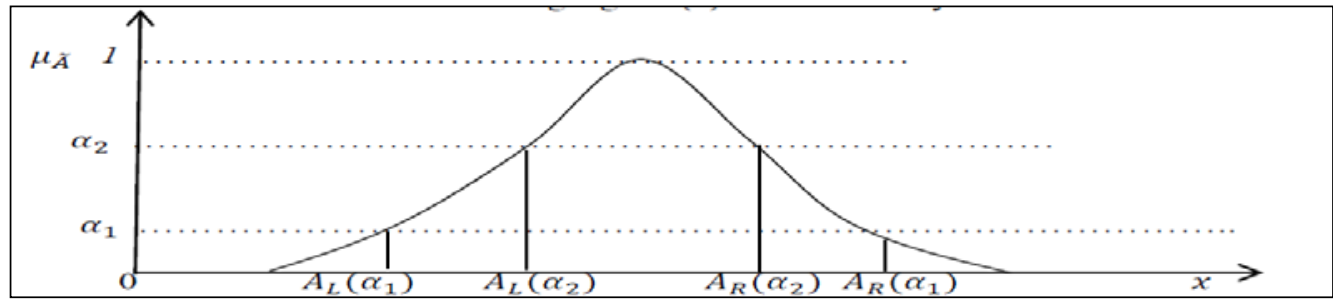

Figure 1: Fuzzy Number $\widetilde{A}$ with a-cuts.

Above figure-1 shows a fuzzy number $\widetilde{A}$ with a-cuts $A_{\alpha_{1}}=\left[A_{L}\left(\alpha_{1}\right), A_{R}\left(\alpha_{1}\right)\right]$, $A_{\alpha_{2}}=\left[A_{L}\left(\alpha_{2}\right), A_{R}\left(\alpha_{2}\right)\right]$. It is seen that if $\alpha_{2} \geq \alpha_{1}$ then $A_{L}\left(\alpha_{2}\right) \geq A_{L}\left(\alpha_{1}\right)$ and $A_{R}\left(\alpha_{2}\right) \geq A_{R}\left(\alpha_{1}\right)$.

- Definition 2.6: Among the various shapes of fuzzy number, triangular fuzzy number (TFN) is the most popular one. $\widetilde{A}$ is represented by the triplet $\left(a_{1}, a_{2}\right.$, $\left.a_{3}\right)$ and is defined by its continuous membership function where $\mu_{\tilde{A}}(\mathrm{x}): \mathrm{X} \rightarrow[0,1]$ is given by

$$
\mu_{\tilde{A}}(\mathrm{x})=f(\mathrm{x})=\left\{\begin{array}{cl}
1-\frac{a_{2}-x}{a_{2}-a_{1}}, & \text { for } a_{1} \leq x \leq a_{2} \\
1, & \text { for } x=a_{2} \\
1-\frac{x-a_{2}}{a_{3}-a_{2}}, & \text { for } a_{2} \leq x \leq a_{3} \\
0, & \text { for Otherwise }
\end{array}\right.
$$

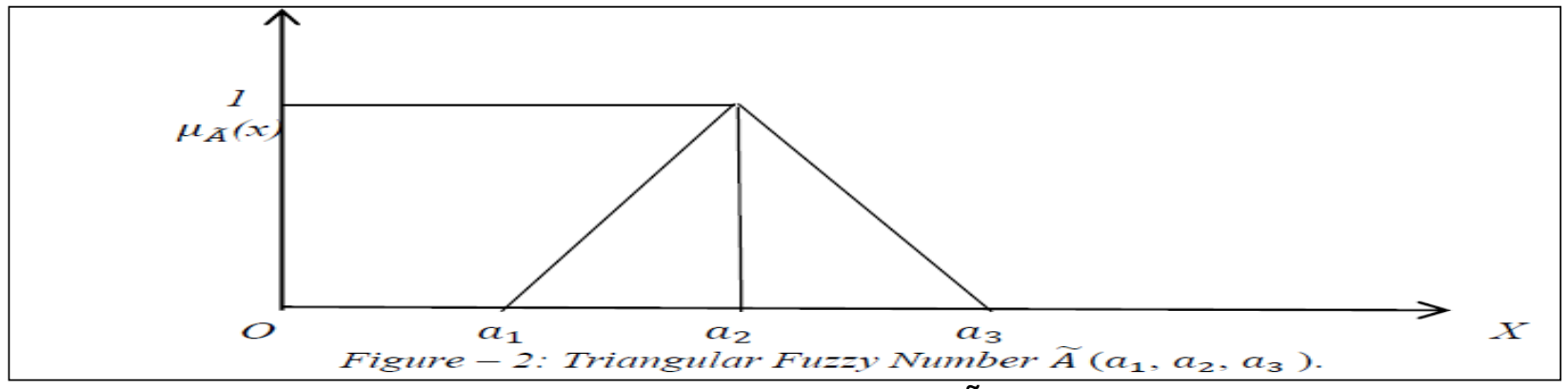

Figure 2: Triangular Fuzzy Number $\tilde{A}\left(a_{1}, a_{2}, a_{3}\right)$

- Definition 2.7: An interval number $A$ is defined by an order pair of real numbers as follows: $A=\left[a_{L}, a_{R}\right]=\left\{x: a_{L} \leq x \leq a_{R}, x \in \Re\right\}$. Where $a_{L}$ and $a_{R}$ are the left and right bounds of interval of $A$, respectively. The interval $A$, is also defined by centre $\left(a_{C}\right)$ and half-width $\left(a_{W}\right)$ as follows: $A=\left\langle a_{C}, a_{W}\right\rangle=\left\{x: a_{C}-a_{W} \leq x \leq\right.$ $\left.a_{C}+a_{W}, x \in \Re\right\}$, where $a_{C}=\frac{a_{R}+a_{L}}{2}$ is the centre and $a_{W}=\frac{a_{R}-a_{L}}{2}$ is half-width of A.

- Definition 2.8: Here, we will propose interval approximation operator called the nearest interval approximation which approximates a fuzzy number by a crisp model. Suppose, $\tilde{A}$ and $\tilde{B}$ be two fuzzy numbers with $\alpha-$ cuts are $\left[A_{L}(\alpha), A_{R}(\alpha)\right]$ 
and $\left[B_{L}(\alpha), B_{R}(\alpha)\right]$ respectively. Then the Euclidean distance between $\tilde{A}$ and $\tilde{B}$ is

$$
d(\tilde{A}, \tilde{B})=\sqrt{\int_{0}^{1}\left(A_{L}(\alpha)-B_{L}(\alpha)\right)^{2} d \alpha+\int_{0}^{1}\left(A_{R}(\alpha)-B_{R}(\alpha)\right)^{2} d \alpha}
$$

Given $\tilde{A}$ is a fuzzy number whose $\alpha-$ cuts are $\left[A_{L}(\alpha), A_{R}(\alpha)\right]$. We have to find a closed interval a closed interval $C_{d}(\tilde{A})$ which is the nearest to $\tilde{A}$ with respect to metric $d$. We can do it since each interval is also a fuzzy number with constant $\alpha$-cut for all $\alpha \in(0,1]$. Hence, let $C_{d}(\tilde{A})=\left[C_{L}, C_{R}\right]$, i.e. $\left(C_{d}(\tilde{A})\right)_{\alpha}=\left[C_{L}, C_{R}\right]$, $\forall \alpha \in(0,1]$. Now we have to minimize

$$
d\left(\tilde{A}, C_{d}(\tilde{A})\right)=\sqrt{\int_{0}^{1}\left(A_{L}(\alpha)-C_{L}\right)^{2} d \alpha+\int_{0}^{1}\left(A_{R}(\alpha)-C_{R}\right)^{2} d \alpha}
$$

with respect to $C_{L}$ and $C_{R}$.

In order to minimize $d\left(\tilde{A}, C_{d}(\tilde{A})\right)$ it is sufficient to minimize function $D\left(C_{L}, C_{R}\right)\left(=d^{2}\left(\tilde{A}, C_{d}(\tilde{A})\right)\right)$. Thus we have to find partial derivatives

$\frac{\partial D\left(C_{L}, C_{R}\right)}{\partial C_{L}}=-2 \int_{0}^{1}\left(A_{L}(\alpha)-C_{L}\right) d \alpha=-2 \int_{0}^{1} A_{L}(\alpha) d \alpha+2 C_{L}$.

And $\frac{\partial D\left(C_{L}, C_{R}\right)}{\partial C_{R}}=-2 \int_{0}^{1}\left(A_{R}(\alpha)-C_{R}\right) d \alpha=-2 \int_{0}^{1} A_{R}(\alpha) d \alpha+2 C_{R}$.

and then to solve $\frac{\partial D\left(C_{L}, C_{R}\right)}{\partial C_{L}}=0$ and $\frac{\partial D\left(C_{L}, C_{R}\right)}{\partial C_{R}}=0$.

The solution is

$C_{L}{ }^{*}=\int_{0}^{1} A_{L}(\alpha) d \alpha$ and $C_{R}{ }^{*}=\int_{0}^{1} A_{R}(\alpha) d \alpha$

Moreover, since

$$
\operatorname{det}\left[\begin{array}{ll}
\frac{\partial D^{2}\left(C_{L}{ }^{*}, C_{R}{ }^{*}\right)}{\partial C_{L}{ }^{* 2}} & \frac{\partial D^{2}\left(C_{L}{ }^{*}, C_{R}{ }^{*}\right)}{\partial C_{R}{ }^{*} \partial C_{L}{ }^{*}} \\
\frac{\partial D^{2}\left(C_{L}{ }^{*}, C_{R}{ }^{*}\right)}{\partial C_{L}{ }^{*} \partial C_{R}{ }^{*}} & \frac{\partial D^{2}\left(C_{L}{ }^{*}, C_{R}{ }^{*}\right)}{\partial C_{R}{ }^{* 2}}
\end{array}\right]=\operatorname{det}\left[\begin{array}{ll}
2 & 0 \\
0 & 2
\end{array}\right]=4>0
$$

So, $D\left(C_{L}, C_{R}\right)$ i.e.d $\left(\tilde{A}, C_{d}(\tilde{A})\right)$ is global minimum. 
Therefore, the interval $C_{d}(\tilde{A})=\left[\int_{0}^{1} A_{L}(\alpha) d \alpha, \int_{0}^{1} A_{R}(\alpha) d \alpha\right]=\left[C_{L}{ }^{*}, C_{R}{ }^{*}\right]$ is indeed the nearest interval approximation of fuzzy number $\tilde{A}$ with respect to metric $\mathrm{d}$.

- Definition 2.9: Let, $\tilde{A}=\left(a_{1}, a_{2}, a_{3}\right)$ be a fuzzy number. The $\alpha$-level interval of $\tilde{A}$ is defined as $(\tilde{A})_{\alpha}=\left[A_{L}(\alpha), A_{R}(\alpha)\right]$. When $\tilde{A}$ is a triangular fuzzy number (TFN) then $A_{L}(\alpha)=a_{1}+\alpha\left(a_{2}-a_{1}\right)$ and $A_{R}(\alpha)=a_{2}-\alpha\left(a_{3}-a_{2}\right)$.

By the nearest interval approximation method the lower limit of the interval is $C_{L}=\int_{0}^{1} A_{L}(\alpha) d \alpha=\int_{0}^{1}\left(a_{1}+\alpha\left(a_{2}-a_{1}\right)\right) d \alpha=\frac{a_{1}+a_{2}}{2}$.

and the upper limit of the interval is $C_{R}=\int_{0}^{1} A_{R}(\alpha) d \alpha=\int_{0}^{1}\left(a_{2}-\alpha\left(a_{3}-a_{2}\right)\right) d \alpha=\frac{a_{2}+a_{3}}{2}$.

Therefore, the interval number considering $\tilde{A}$ as a TFN, is $\left[\frac{a_{1}+a_{2}}{2}, \frac{a_{2}+a_{3}}{2}\right]$. In the centre and half-width form the interval number of $\tilde{A}$ is defined as $\left\langle\frac{a_{1}+2 a_{2}+a_{3}}{4}, \frac{a_{1}-a_{3}}{4}\right\rangle$.

- Definition 2.10: Let $\left[a_{L}, a_{R}\right]$ be an interval, where $a_{L}>0, a_{R}>0$. If one assumes (according to Carlsson and Korhonen [16] )that for the possible values of the parameters in the form $\left[I^{0}, I^{1}\right]$, where the lower bounds represent 'risk-free' values in the sense that a solution most certainly should be implementable and the upper bounds, on the other hand, represent parameter values which are most certainly unrealistic, 'impossible' and the solution obtained by using these values is not implementable. When we move from 'risk-free' towards 'impossible' parameter values, we move from solutions with a high grade to solutions with a low grade on implementing - from 'secure' to 'optimistic' solutions. Our task is to find an optimal compromise 'in-between' as a function of the grades of imprecision in the parameters. Also, we can express an interim by a function. So the parametric interim -valued function for the interim $\left[a_{L}, a_{R}\right]$ can be taken as $f(v)=a_{L}^{1-v} a_{R}^{v}$ for $v \in[0,1]$, which is an entirely monotone, continuous function and its reverse ways out.

\section{Mathematical Model}

This inventory model is developed on the basis of the following Assumptions and Notations which are used throughout this paper in Crisp and Fuzzy Environment.

\subsection{Notations:}


- $I_{i}(\mathrm{t})$ : The inventory level in phase iat any time point $\mathrm{t}, \mathrm{i}=1,2,3,4$ and $\mathrm{t} \geq 0$.

- $l p$ : Production cost per unit per unit time.

- $u$ : Defective units per cycle.

- $d$ : The unit discount rate.

- $C_{s}$ : The fixed set-up cost of the inventory.

- $C_{b}$ : The shortage cost for backlogged items per unit per unit time.

- $C_{a}$ : The advertisement cost per advertisement.

- $C_{c}$ : Total amount of capital investment per cycle.

- $\mathrm{Q}\left(=L_{M}+L_{b}\right):$ The order quantity during a cycle period.

- $M$ : Thetrade credit transaction deadline.

- $I_{e}$ :The interest earned for unit fund.

- $I_{p}:$ The interest yielded for unit fund.

- $t_{1}$ : The production time when the quality of products in stock reaches maximum $L_{m}$.

- $t_{2}$ : The deteriorating time period when inventory diminished gradually to zero.

- $t_{3}$ : The time period when shortages reaches maximum $L_{b}$.

- $t_{4}$ : The time period when the production again starts and the inventory gradually reached to zero.

- $\operatorname{Tac}\left(t_{2}^{*}, t_{3}^{*}\right):$ The total average cost per unit per cycle.

\subsection{Assumptions:}

- The demand rate $D(s, f, p)=\frac{s f^{r}}{p}$ is dependent on display display shelfspace(s), selling price (p) of an item and the frequency of advertisement (f), where $s, p, f>0$.

- Production rate $P(k, s, f, p)=k D(s, f, p)=k \frac{s f^{r}}{p}$, where $\mathrm{k}$ is a constant.

- Holding cost is $e^{-\alpha t}$ per unit per unit time. 
DOI: 10.14807/ijmp.v10i3.865

- The horizontal planning takes place at an infinite rate.

- Shortages are allowed and fully backlogged.

- Lead time is zero or negligible.

- There is no replenishment or repair of deteriorating and defective items takes place in the given cycle.

\subsection{Mathematical formulation}

Let, the manufacturer start to produce items to satisfy the arriving demands in the inventory system at the beginning of each cycle when $t=0$. At end of $t_{1}$, the production stopped when the inventory level reached to $L_{m}(>0)$. The inventory level diminishes owing to customer demand and deterioration and finally falls to zero at $\mathrm{t}$ $=t_{2}$. Let, the maximum shortage level reached to $L_{b}$ at $t=t_{3}$ and at the end of the time $t_{3}$ the manufacturer again start produces the items. Finally, the inventory level gradually reached to zeroat $t=t_{4}$. Figure -3 depicts the inventory level of the proposed model.

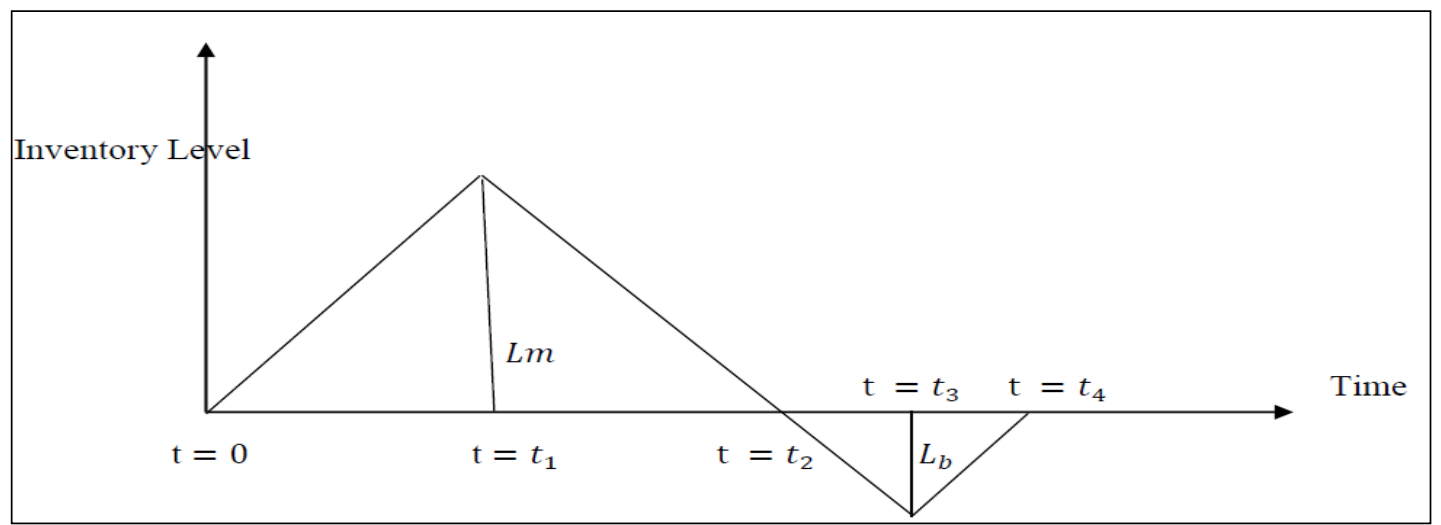

Figure 3: Graphical Representation of Inventory System

According to figure-3, the inventory partitions as follows:

a) The Inventory Level in $t_{1}\left(0 \leq t \leq t_{1}\right)$ : The inventory level during $\left[0, t_{1}\right]$ increases gradually due to the instant demand $(D)$ as well as defective items and reaches to its maximum level $L_{m}$. Under above assumption, during the period $\left[0, t_{1}\right]$, the inventory status of the system is given by the following differential equation$\frac{d I_{1}(t)}{d t}=k \frac{s f^{r}}{p}-\frac{s f^{r}}{p}-u, \quad$ for $\left(0 \leq \mathrm{t} \leq \mathrm{t}_{1}\right)$

With the initial Condition $I_{1}(0)=0$ and the boundary condition $I_{1}\left(t_{1}\right)=L_{m}$, get from above equation (3.4.1), 
DOI: 10.14807/ijmp.v10i3.865

$$
\begin{aligned}
& I_{1}(t)=\left(k \frac{s f^{r}}{p}-\frac{s f^{r}}{p}-u\right) t \\
& \text { And } L_{m}=\left(k \frac{s f^{r}}{p}-\frac{s f^{r}}{p}-u\right) t_{1}
\end{aligned}
$$

b) The Inventory Level in $t_{2}\left(t_{1} \leq t \leq t_{1}+t_{2}\right)$ : In $t_{2}$, the inventory decreases due to customers' demand and deterioration. Hence, the status of the inventory level during $\left(t_{1}, t_{1}+t_{2}\right)$ is governed by the following Differential Equation,

$\frac{d I_{2}(t)}{d t}+\alpha I_{2}(t)=-\frac{s f^{r}}{p}, \quad$ for $\left(t_{1} \leq t \leq t_{1}+t_{2}\right)$

With the help of the Conditions $I_{2}\left(t_{1}\right)=L_{m}, I_{2}\left(t_{1}+t_{2}\right)=0$, we get from above equation (3.4.4),

$I_{2}(t)=\frac{s f^{r}}{\alpha p}\left[e^{\alpha\left(t_{1}+t_{2}-t\right)}-1\right]$

And $L_{m}=\frac{s f^{r}}{\alpha p}\left[e^{\alpha t_{2}}-1\right]$

c) The Inventory Level in $t_{3}\left(t_{1}+t_{2} \leq t \leq t_{1}+t_{2}+t_{3}\right)$ : At the end of time $t_{1}+$ $t_{2}$ the inventory level reaches to zero and shortages occurs. During the interval $\left(t_{1}+t_{2}, t_{1}+t_{2}+t_{3}\right)$, the inventory level depends on demand and the demand is fully backlogged. The status of the inventory level during this period is governed by the following Differential Equation-

$\frac{d I_{3}(t)}{d t}=-\frac{s f^{r}}{p}, \quad$ for $\left(t_{1}+t_{2} \leq t \leq t_{1}+t_{2}+t_{3}\right)$

With the Conditions $I_{3}\left(t_{1}+t_{2}\right)=0$ and $-I_{3}\left(t_{1}+t_{2}+t_{3}\right)=L_{b}$, we get from above equation (3.4.7),

$I_{3}(t)=\frac{s f^{r}}{p}\left(t_{1}+t_{2}-t\right)$

And $L_{b}=-I_{3}\left(t_{1}+t_{2}+t_{3}\right)=\frac{s f^{r}}{p} t_{3}$

d) The Inventory Level in $t_{4}\left(t_{1}+t_{2}+t_{3} \leq t \leq t_{1}+t_{2}+t_{3}+t_{4}\right)$ : At the time point $t_{1}+t_{2}+t_{3}$,the production of the items again starts and backlog would be completely cleared to the next replenishment cycle. Under above assumption, during this period $\left[t_{1}+t_{2}+t_{3}, t_{1}+t_{2}+t_{3}+t_{4}\right]$, the inventory status of the system is given by the following Differential Equation- 
DOI: 10.14807/ijmp.v10i3.865

$$
\frac{d I_{4}(t)}{d t}=-k \frac{s f^{r}}{p}+\frac{s f^{r}}{p}+u, \quad \text { for }\left(t_{1}+t_{2}+t_{3} \leq t \leq t_{1}+t_{2}+t_{3}+t_{4}\right)
$$

With the boundary Conditions $-I_{4}\left(t_{1}+t_{2}+t_{3}\right)=L_{b}$ and $I_{4}\left(t_{1}+t_{2}+t_{3}+t_{4}\right)=$ 0 , get from above equation (3.4.10),

$$
I_{4}(t)=\left(k \frac{s f^{r}}{p}-\frac{s f^{r}}{p}-u\right)\left(t_{1}+t_{2}+t_{3}+t_{4}-t\right)
$$

And $L_{b}=-\left(k \frac{s f^{r}}{p}-\frac{s f^{r}}{p}-u\right) t_{4}$

Also, we have $t_{1}=\frac{\frac{s f^{r}}{\alpha p}\left[e^{\left.\alpha t_{2}-1\right]}\right.}{\left(k \frac{s f^{r}}{p}-\frac{s f^{r}}{p}-u\right)}=\mathrm{a}\left(\right.$ Say) and $t_{4}=\frac{-\frac{s f^{r}}{p} t_{3}}{\left(k \frac{s f^{r}}{p}-\frac{s f^{r}}{p}-u\right)}=\mathrm{b}$ (Say)

Thus the order size during total time interval $\left[0, t_{1}+t_{2}+t_{3}+t_{4}\right]$ is

$$
\mathrm{Q}=L_{m}+L_{b}=\frac{s f^{r}}{\alpha p}\left[e^{\alpha t_{2}}-1\right]+\frac{s f^{r}}{p} t_{3}
$$

According to above discussion, the following cost function can be derived.

1 The set-up cost during the cycle: $C_{s}$

2 The production cost during the cycle: $k s f^{r} l\left(t_{1}+t_{4}\right)$

3 The Inventory Holding cost during the period $\left[0, t_{1}+t_{2}\right]$ :

$$
\begin{aligned}
& \int_{0}^{t_{1}} e^{-\alpha t} I_{1}(t) d t+\int_{t_{1}}^{t_{1}+t_{2}} e^{-\alpha t} I_{2}(t) d t=\left(k \frac{s f^{r}}{p}-\frac{s f^{r}}{p}-u\right)\left(\frac{t_{1}^{2}}{2}-\alpha \frac{t_{1}{ }^{3}}{3}\right)+\frac{s f^{r}}{p}\left[\frac{\left(t_{1}+t_{2}\right)^{2}}{2}-\right. \\
& \left.t_{1} t_{2}-\frac{t_{1}{ }^{2}}{2}\right]
\end{aligned}
$$

4 The Deteriorating cost during the period $\left[t_{1}, t_{1}+t_{2}\right]$ :

$$
\operatorname{lp}\left[L_{m^{-}}-\int_{t_{1}}^{t_{1}+t_{2}} \frac{s f^{r}}{p} d t\right]=l \frac{s f^{r}}{\alpha}\left[e^{\alpha t_{2}}-1\right]-l s f^{r} t_{2}
$$

5 The shortage cost per cycle : $-C_{b} \int_{t_{1}+t_{2}}^{t_{1}+t_{2}+t_{3}} I_{3}(t) d t-C_{b} \int_{t_{1}+t_{2}+t_{3}}^{t_{1}+t_{2}+t_{3}+t_{4}} I_{4}(t) d t=$

$$
\begin{aligned}
& -C_{b} \frac{s f^{r}}{p}\left[\left(t_{1}+t_{2}+t_{3}\right) \frac{\left(t_{1}+t_{2}-t_{3}\right)}{2}-\frac{\left(t_{1}+t_{2}\right)^{2}}{2}\right]-C_{b}\left(k \frac{s f^{r}}{p}-\frac{s f^{r}}{p}-u\right)\left[\frac{\left(t_{1}+t_{2}+t_{3}+t_{4}\right)^{2}}{2}-\right. \\
& \left.\left(t_{1}+t_{2}+t_{3}\right) \frac{\left(t_{1}+t_{2}+t_{3}+2 t_{4}\right)}{2}\right](3.4 .19)
\end{aligned}
$$

6 The advertisement cost during the cycle: $C_{a} f$

7 The price discount during the period $\left[t_{1}, t_{1}+t_{2}\right]: l p d \int_{t_{1}}^{t_{1}+t_{2}} \frac{s f^{r}}{p} d t=l d s f^{r} t_{2}$ 
INDEPENDENT JOURNAL OF MANAGEMENT \& PRODUCTION (IJM\&P)

http://www.ijmp.jor.br

v. 10, n. 3, May - June 2019

ISSN: 2236-269X

DOI: 10.14807/ijmp.v10i3.865

Now, we will discuss the following two cases:

Case-1: When $0 \leq M \leq t_{1}+t_{2}$.

For $0 \leq M \leq t_{1}+t_{2}$, the length of permissible delay in payment (M) when the account is not settled, the retailer sells the goods and continues to accumulate sales revenue and earned the interest with rate $I_{e}$ during $\left(0, t_{1}+t_{2}\right)$. Therefore, the interest earned in the cycle period is

$$
\begin{aligned}
& I_{1} E=l p I_{e} \int_{0}^{t 1} k s \frac{f^{r}}{p} d t+p I_{e} \int_{0}^{t_{1}+t_{2}} s \frac{f^{r}}{p} d t+I_{e} \int_{t 1+t 2+t 3}^{t 1+t 2+t 3+t 4}\left(p s \frac{f^{r}}{p}-l p k s \frac{f^{r}}{p}\right) d t \\
& =l I_{e} k s f^{r} t_{1}+I_{e} s f^{r}\left(t_{1}+t_{2}\right)+I_{e}\left(s f^{r}-l k s f^{r}\right) t_{4}
\end{aligned}
$$

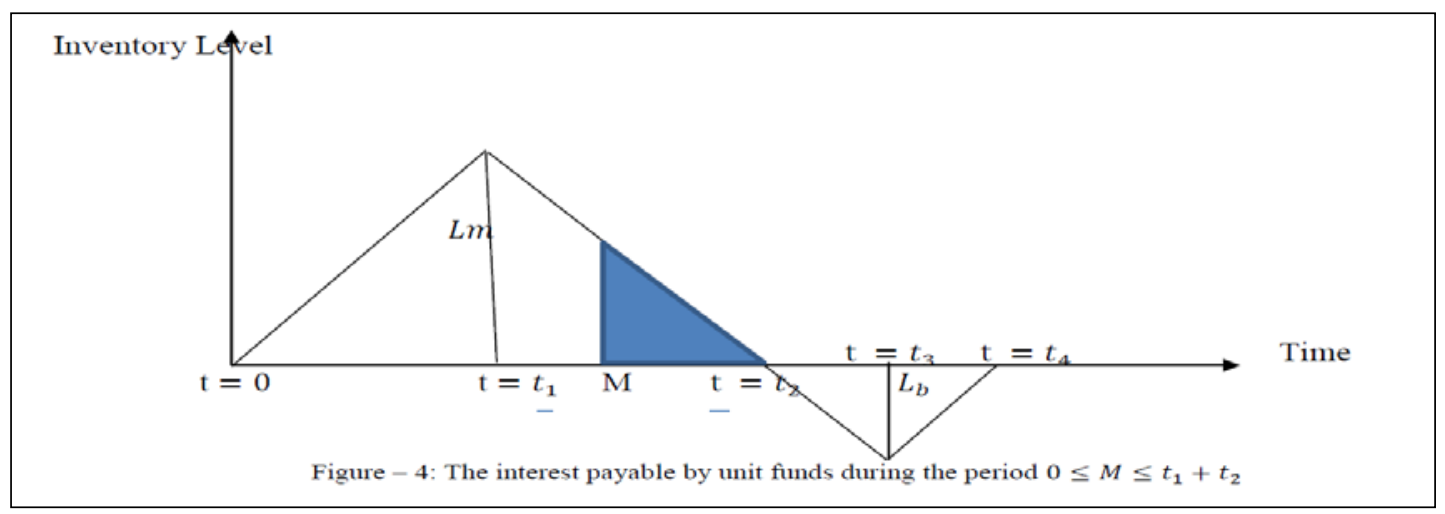

Figure 4: The interest payable by unit funds during the period

Beyond the fixed settlement period, the unsold stock is financed with an interest rate $I_{p}$. Based on figure-4, the interest payable at this time when products in stock as follow:

$I_{1} P=l p I_{p} \int_{M}^{t_{1}+t_{2}} \frac{s f^{r}}{p}\left(t_{1}+t_{2}-t\right) d t=l I_{p} s f^{r}\left[\frac{\left(t_{1}+t_{2}\right)^{2}}{2}-M t_{1}-M t_{2}+\frac{M^{2}}{2}\right]$

According to aforesaid definition of total cost, the total average net cost function as follows:

$$
\begin{aligned}
& \operatorname{Tac}_{1}\left(t_{1}, t_{2}, t_{3}, t_{4}\right)=\frac{1}{\left(t_{1}+t_{2}+t_{3}+t_{4}\right)}\left[\bar{C}_{s}+k s f^{r} l\left(\bar{t}_{1}+t_{4}\right)+\left(k \frac{s f^{r}}{p}-\frac{s f^{r}}{p}-u\right)\left(\frac{t_{1}^{2}}{2}-\alpha \frac{t_{1}{ }^{3}}{3}\right)+\right. \\
& \frac{s f^{r}}{p}\left[\frac{\left(t_{1}+t_{2}\right)^{2}}{2}-t_{1} t_{2}-\frac{t_{1}^{2}}{2}\right]+l \frac{s f^{r}}{\alpha}\left[e^{\alpha t_{2}}-1\right]-l s f^{r} t_{2}-C_{b} \frac{s f^{r}}{p}\left[\left(t_{1}+t_{2}+t_{3}\right) \frac{\left(t_{1}+t_{2}-t_{3}\right)}{2}-\right. \\
& \left.\frac{\left(t_{1}+t_{2}\right)^{2}}{2}\right]-C_{b}\left(k \frac{s f^{r}}{p}-\frac{s f^{r}}{p}-u\right)\left[\frac{\left(t_{1}+t_{2}+t_{3}+t_{4}\right)^{2}}{2}-\left(t_{1}+t_{2}+\right.\right. \\
& \left.\left.t_{3}\right) \frac{\left(t_{1}+t_{2}+t_{3}+2 t_{4}\right)}{2}\right]+C_{a} f+l d s f^{r} t_{2}+l I_{p} s f^{r}\left[\frac{\left(t_{1}+t_{2}\right)^{2}}{2}-M t_{1}-M t_{2}+\frac{M^{2}}{2}\right]-l I_{e} k s f^{r} t_{1}- \\
& \left.I_{e} s f^{r}\left(t_{1}+t_{2}\right)-I_{e}\left(s f^{r}-l k s f^{r}\right) t_{4}\right]
\end{aligned}
$$


DOI: 10.14807/ijmp.v10i3.865

Subject to, $k\left(t_{1}+t_{4}\right) \geq \frac{1}{\alpha}\left[e^{\alpha t_{2}}-1\right]+t_{3}$

$$
C_{c} \geq \frac{l s f^{r}}{\alpha}\left[e^{\alpha t_{2}}-1\right]+l s f^{r} t_{3}
$$

Therefore, using equation (3.4.13), the equations (3.4.24) reduced to

$$
\begin{aligned}
& \operatorname{Tac}_{1}\left(t_{2}, t_{3}\right)=\frac{1}{\left(a+t_{2}+t_{3}+b\right)}\left[C_{s}+k s f^{r} l(a+b)+\left(k \frac{s f^{r}}{p}-\frac{s f^{r}}{p}-u\right)\left(\frac{a^{2}}{2}-\alpha \frac{a^{3}}{3}\right)+\frac{s f^{r}}{p}\left[\frac{\left(a+t_{2}\right)^{2}}{2}-\right.\right. \\
& \left.a t_{2}-\frac{a^{2}}{2}\right]+l \frac{s f^{r}}{\alpha}\left[e^{\alpha t_{2}}-1\right]-l s f^{r} t_{2}-C_{b} \frac{s f^{r}}{p}\left[\left(a+t_{2}+t_{3}\right) \frac{\left(a+t_{2}-t_{3}\right)}{2}-\frac{\left(a+t_{2}\right)^{2}}{2}\right]-C_{b}\left(k \frac{s f^{r}}{p}-\right. \\
& \left.\frac{s f^{r}}{p}-u\right)\left[\frac{\left(a+t_{2}+t_{3}+b\right)^{2}}{2}-\left(a+t_{2}+t_{3}\right) \frac{\left(a+t_{2}+t_{3}+2 b\right)}{2}\right]+C_{a} f+l d s f^{r} t_{2}+l I_{p} s f^{r}\left[\frac{\left(a+t_{2}\right)^{2}}{2}-\right. \\
& \left.\left.M a-M t_{2}+\frac{M^{2}}{2}\right]-l I_{e} k s f^{r} a-I_{e} s f^{r}\left(a+t_{2}\right)-I_{e}\left(s f^{r}-l k s f^{r}\right) b\right]
\end{aligned}
$$

Subject to, $k(a+b) \geq \frac{1}{\alpha}\left[e^{\alpha t_{2}}-1\right]+t_{3}$

$$
C_{c} \geq \frac{l s f^{r}}{\alpha}\left[e^{\alpha t_{2}}-1\right]+l s f^{r} t_{3}
$$

Now, the necessary condition for the total average cost of the system is minimize if equation (3.4.25) is satisfy,

$$
\begin{aligned}
& \frac{\partial \operatorname{Tac}_{1}\left(t_{2}, t_{3}\right)}{\partial t_{2}}=0, \\
& \text { And } \frac{\partial T a c_{1}\left(t_{2}, t_{3}\right)}{\partial t_{3}}=0,
\end{aligned}
$$

The solution, which may be called feasible solution of the problem, of the equations (3.4.26) and (3.4.27) give the optimal solutions of $t_{2}=t_{2}^{*}$ and $t_{3}=t_{3}^{*}$ which minimize $\operatorname{Tac}_{1}\left(t_{2}, t_{3}\right)=\operatorname{Tac}_{1}\left(t_{2}{ }^{*}, t_{3}{ }^{*}\right)^{*}$ provide they satisfy the sufficient conditions-

$$
\begin{aligned}
& \frac{\partial^{2} T a c_{1}\left(t_{2}, t_{3}\right)}{\partial t_{2}^{2}} \cdot \frac{\partial^{2} T a c_{1}\left(t_{2}, t_{3}\right)}{\partial t_{3}{ }^{2}}-\left(\frac{\partial^{2} T a c_{1}\left(t_{2}, t_{3}\right)}{\partial t_{2} \partial t_{3}}\right)^{2}>0 \\
& \text { And } \frac{\partial^{2} T a c_{1}\left(t_{2}, t_{3}\right)}{\partial t_{2}^{2}}>0 \text { or, } \frac{\partial^{2} T a c_{1}\left(t_{2}, t_{3}\right)}{\partial t_{3}^{2}}>0
\end{aligned}
$$

However, it's difficult to solve the problem by deriving an explicit equation of the solutions from equations (3.4.26) and (3.4.27). Therefore, we solve the optimal service level of $t_{2}=t_{2}^{*}$ and $t_{3}=t_{3}^{*}$ and minimum value of $\operatorname{Tac}_{1}\left(t_{2}, t_{3}\right)$ by using the software LINGO 17.0. Moreover, we also verify that the sufficient conditions of the optimality of 
INDEPENDENT JOURNAL OF MANAGEMENT \& PRODUCTION (IJM\&P)

http://www.ijmp.jor.br

v. 10, n. 3, May - June 2019

ISSN: 2236-269X

DOI: 10.14807/ijmp.v10i3.865

the solutions of $t_{2}=t_{2}^{*}$ and $t_{3}=t_{3}^{*}$ are satisfied under certain conditions ( $i . e$. inequalities (3.4.28) and (3.4.29)).

Case-2: When $t_{1}+t_{2}<M \leq t_{1}+t_{2}+t_{3}+t_{4}$.

For $t_{1}+t_{2}<M \leq t_{1}+t_{2}+t_{3}+t_{4}$, the length of permissible delay in payment (M) is more than the period with no deterioration and the period with positive inventory $\left(t_{1}+t_{2}\right)$ when the account is not settled, the retailer sells the goods and continues to accumulate sales revenue and earned the interest with rate $I_{e}$ during $\left(0, t_{1}+t_{2}\right)$.

Therefore, the interest earned in the cycle period is

$$
\begin{gathered}
I_{2} E=l p I_{e} \int_{0}^{t 1} k s \frac{f^{r}}{p} d t+p I_{e} \int_{0}^{t_{1}+t_{2}} s \frac{f^{r}}{p} d t+I_{e} \int_{t 1+t 2+t 3}^{t 1+t 2+t 3+t 4}\left(p s \frac{f^{r}}{p}-l p k s \frac{f^{r}}{p}\right) d t \\
=l I_{e} k s f^{r} t_{1}+I_{e} s f^{r}\left(t_{1}+t_{2}\right)+I_{e}\left(s f^{r}-l k s f^{r}\right) t_{4}
\end{gathered}
$$

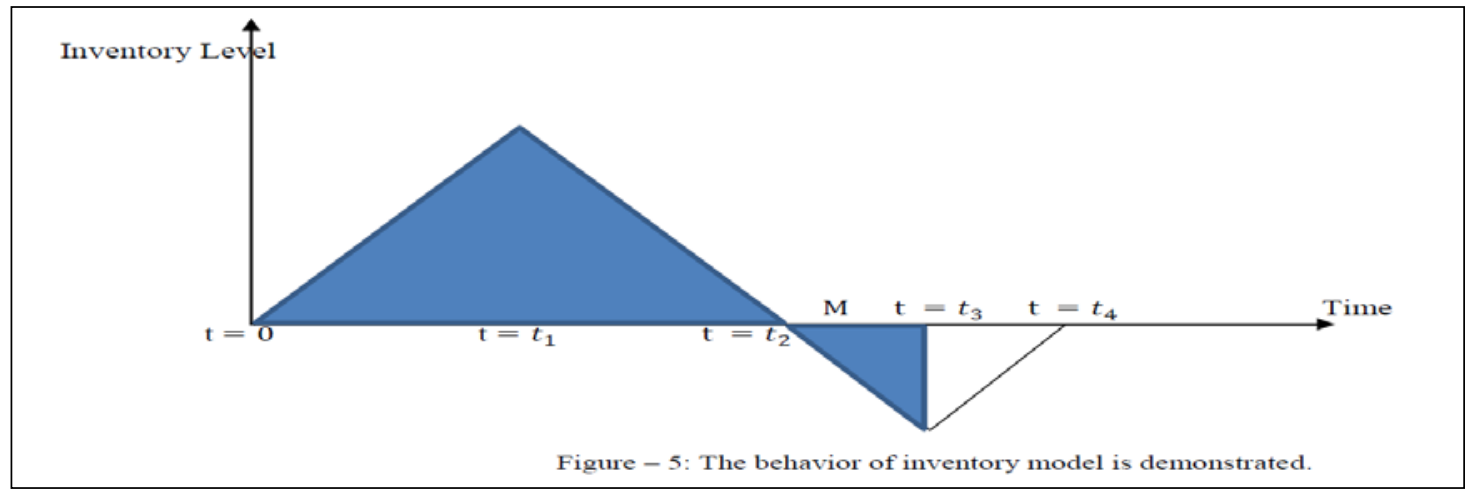

Figure 5: The behavior of inventory model is demonstrated

According to aforesaid definition of total cost, the total average net cost function as follows: $\operatorname{Tac}_{2}\left(t_{1}, t_{2}, t_{3}, t_{4}\right)=\frac{1}{\left(t_{1}+t_{2}+t_{3}+t_{4}\right)}\left[C_{s}+k s f^{r} l\left(t_{1}+t_{4}\right)+\left(k \frac{s f^{r}}{p}-\frac{s f^{r}}{p}-u\right)\left(\frac{t_{1}^{2}}{2}-\right.\right.$ $\left.\alpha \frac{t_{1}{ }^{3}}{3}\right)+\frac{s f^{r}}{p}\left[\frac{\left(t_{1}+t_{2}\right)^{2}}{2}-t_{1} t_{2}-\frac{t_{1}{ }^{2}}{2}\right]+l \frac{s f^{r}}{\alpha}\left[e^{\alpha t_{2}}-1\right]-l s f^{r} t_{2}-C_{b} \frac{s f^{r}}{p}\left[\left(t_{1}+t_{2}+\right.\right.$ $\left.\left.t_{3}\right) \frac{\left(t_{1}+t_{2}-t_{3}\right)}{2}-\frac{\left(t_{1}+t_{2}\right)^{2}}{2}\right]-C_{b}\left(k \frac{s f^{r}}{p}-\frac{s f^{r}}{p}-u\right)\left[\frac{\left(t_{1}+t_{2}+t_{3}+t_{4}\right)^{2}}{2}-\left(t_{1}+t_{2}+\right.\right.$ $\left.\left.\left.t_{3}\right) \frac{\left(t_{1}+t_{2}+t_{3}+2 t_{4}\right)}{2}\right]+C_{a} f+l d s f^{r} t_{2}-l I_{e} k s f^{r} t_{1}-I_{e} s f^{r}\left(t_{1}+t_{2}\right)-I_{e}\left(s f^{r}-l k s f^{r}\right) t_{4}\right]$

Subject to, $k(a+b) \geq \frac{1}{\alpha}\left[e^{\alpha t_{2}}-1\right]+t_{3}$

$$
C_{c} \geq \frac{l s f^{r}}{\alpha}\left[e^{\alpha t_{2}}-1\right]+l s f^{r} t_{3}
$$

Therefore, using equation (3.4.13), the equations (3.4.31) reduced to 
DOI: 10.14807/ijmp.v10i3.865

$$
\begin{aligned}
& \operatorname{Tac}_{2}\left(t_{2}, t_{3}\right)=\frac{1}{\left(a+t_{2}+t_{3}+b\right)}\left[C_{s}+k s f^{r} l(a+b)+\left(k \frac{s f^{r}}{p}-\frac{s f^{r}}{p}-u\right)\left(\frac{a^{2}}{2}-\alpha \frac{a^{3}}{3}\right)+\right. \\
& \frac{s f^{r}}{p}\left[\frac{\left(a+t_{2}\right)^{2}}{2}-a t_{2}-\frac{a^{2}}{2}\right]+l \frac{s f^{r}}{\alpha}\left[e^{\alpha t_{2}}-1\right]-l s f^{r} t_{2}-C_{b} \frac{s f^{r}}{p}\left[\left(a+t_{2}+t_{3}\right) \frac{\left(a+t_{2}-t_{3}\right)}{2}-\right. \\
& \left.\frac{\left(a+t_{2}\right)^{2}}{2}\right]-C_{b}\left(k \frac{s f^{r}}{p}-\frac{s f^{r}}{p}-u\right)\left[\frac{\left(a+t_{2}+t_{3}+b\right)^{2}}{2}-\left(a+t_{2}+t_{3}\right) \frac{\left(a+t_{2}+t_{3}+2 b\right)}{2}\right]+C_{a} f+l d s f^{r} t_{2}- \\
& \left.l I_{e} k s f^{r} a-I_{e} s f^{r}\left(a+t_{2}\right)-I_{e}\left(s f^{r}-l k s f^{r}\right) b\right]
\end{aligned}
$$

Subject to, $\quad k(a+b) \geq \frac{1}{\alpha}\left[e^{\alpha t_{2}}-1\right]+t_{3}$

$$
C_{c} \geq \frac{l s f^{r}}{\alpha}\left[e^{\alpha t_{2}}-1\right]+l s f^{r} t_{3}
$$

Similarly, the necessary condition for the total average cost of the system is minimize if equation (3.4.32) is satisfy the conditions stated above equations(3.4.26) and (3.4.27)under certain sufficient conditions ( i.e. inequalities (3.4.28) and (3.4.29)).

\subsection{Fuzzy Production Inventory Model}

\section{For Case-1:}

In our inventory model, we have considered that the cost parameters $\widetilde{C_{s}}, \widetilde{C_{b}}, \widetilde{C_{a}}$, $\widetilde{C_{c}}$ and $\tilde{p}$ as a linear fuzzy number. Then the fuzzy numbers are $\widetilde{C_{s}}=\left(C_{s}{ }^{1}, C_{s}{ }^{2}, C_{s}{ }^{3}\right), \widetilde{C_{b}}=$ $\left(C_{b}{ }^{1}, C_{b}{ }^{2}, C_{b}{ }^{3}\right), \widetilde{C_{a}}=\left(C_{a}{ }^{1}, C_{a}{ }^{2}, C_{a}{ }^{3}\right), \widetilde{C_{c}}=\left(C_{c}{ }^{1}, C_{c}{ }^{2}, C_{c}{ }^{3}\right)$ and $\tilde{p}=\left(p^{1}, p^{2}, p^{3}\right)$.

We now form interval numbers for linear fuzzy parameters with the help of the procedureof the nearest interval approximation of a fuzzy number stated above i.e., $\left[C_{s L}, C_{s R}\right],\left[C_{b L}, C_{b R}\right],\left[C_{a L}, C_{a R}\right],\left[C_{a L}, C_{a R}\right]$ and $\left[p_{L}, p_{R}\right]$ and the total average cost is given by

$$
\begin{aligned}
& \left.\operatorname{Tac}_{1} \overline{\left(t_{2}\right.}, t_{3}\right)=\frac{1}{\left(a+t_{2}+t_{3}+b\right)}\left[\left(C_{s L}\right)^{1-v}\left(C_{S R}\right)^{v}+k s f^{r} l(a+b)+\left(k \frac{s f^{r}}{\left(p_{L}\right)^{1-v}\left(p_{R}\right)^{v}}-\frac{s f^{r}}{\left(p_{L}\right)^{1-v}\left(p_{R}\right)^{v}}-\right.\right. \\
& \text { u) }\left(\frac{a^{2}}{2}-\alpha \frac{a^{3}}{3}\right)+\frac{s f^{r}}{\left(p_{L)}{ }^{1-v}\left(p_{R}\right)^{v}\right.}\left[\frac{\left(a+t_{2}\right)^{2}}{2}-a t_{2}-\frac{a^{2}}{2}\right]+l \frac{s f^{r}}{\alpha}\left[e^{\alpha t_{2}}-1\right]-l s f^{r} t_{2} \\
& -\left(C_{b L}\right)^{1-v}\left(C_{b R}\right)^{v} \frac{s f^{r}}{\left(p_{L}\right)^{1-v}\left(p_{R}\right)^{v}}\left[\left(a+t_{2}+t_{3}\right) \frac{\left(a+t_{2}-t_{3}\right)}{2}-\frac{\left(a+t_{2}\right)^{2}}{2}\right]- \\
& \left(C_{b L}\right)^{1-v}\left(C_{b R}\right)^{v}\left(k \frac{s f^{r}}{\left(p_{L}\right)^{1-v}\left(p_{R}\right)^{v}}-\frac{s f^{r}}{\left(p_{L}\right)^{1-v}\left(p_{R}\right)^{v}}-u\right)\left[\frac{\left(a+t_{2}+t_{3}+b\right)^{2}}{2}-\left(a+t_{2}+\right.\right. \\
& \left.\left.t_{3}\right) \frac{\left(a+t_{2}+t_{3}+2 b\right)}{2}\right]+\quad\left(C_{a L}\right)^{1-v}\left(C_{a R}\right)^{v} f+l d s f^{r} t_{2}+l I_{p} s f^{r}\left[\frac{\left(a+t_{2}\right)^{2}}{2}-M a-M t_{2}+\frac{M^{2}}{2}\right]- \\
& \left.l I_{e} k s f^{r} a-I_{e} s f^{r}\left(a+t_{2}\right)-I_{e}\left(s f^{r}-l k s f^{r}\right) b\right]
\end{aligned}
$$


Subject to, $k(a+b) \geq \frac{1}{\alpha}\left[e^{\alpha t_{2}}-1\right]+t_{3}$

$$
\left(C_{c L}\right)^{1-v}\left(C_{c R}\right)^{v} \geq \frac{l s f^{r}}{\alpha}\left[e^{\alpha t_{2}}-1\right]+l s f^{r} t_{3}
$$

Now, the necessary condition for the total average cost of the system is minimize if equation (3.4.33) is satisfy,

$\frac{\left.\partial \operatorname{Tac}_{1\left(t_{2}\right.}, t_{3}\right)}{\partial t_{2}}=0$

And $\frac{\left.\partial T a \widetilde{c_{1}\left(t_{2}\right.}, t_{3}\right)}{\partial t_{3}}=0$,

The solution, which may be called feasible solution of the problem, of the equations (3.4.34) and (3.4.35) give the optimal solutions of $t_{2}=t_{2}^{*}$ and $t_{3}=t_{3}^{*}$ which minimize $\left.\operatorname{Tac}_{1} \overline{\left(t_{2}\right.}, t_{3}\right)=\operatorname{Tac}_{1}\left(\overline{t_{2}{ }^{*},} t_{3}{ }^{*}\right)^{*}$ provide they satisfy the sufficient conditions-

$$
\begin{aligned}
& \frac{\left.\partial^{2} T a \widetilde{c_{1}\left(t_{2}\right.}, t_{3}\right)}{\partial t_{2}^{2}} \cdot \frac{\left.\partial^{2} T a \widetilde{c_{1}\left(t_{2}\right.}, t_{3}\right)}{\partial t_{3}^{2}}-\left(\frac{\left.\partial^{2} T a c_{1} \widetilde{\left(t_{2}\right.}, t_{3}\right)}{\partial t_{2} \partial t_{3}}\right)^{2}>0 \\
& \text { And } \frac{\left.\partial^{2} T a c_{1} \widetilde{\left(t_{2}\right.}, t_{3}\right)}{\partial t_{2}^{2}}>0 \text { or, } \frac{\left.\partial^{2} T a \widetilde{c_{1}\left(t_{2}\right.}, t_{3}\right)}{\partial t_{3}^{2}}>0
\end{aligned}
$$

However, it's difficult to solve the problem by deriving an explicit equation of the solutions from equations (3.4.34) and (3.4.35). Therefore, we solve the optimal service level of $t_{2}=t_{2}^{*}$ and $t_{3}=t_{3}^{*}$ and minimum value of $\operatorname{Tac}_{1}\left(t_{2}, t_{3}\right)$ by using the software LINGO 17.0. Moreover, we also verify that the sufficient conditions of the optimality of the solutions of $t_{2}=t_{2}^{*}$ and $t_{3}=t_{3}^{*}$ are satisfied under certain conditions (i.e. inequalities (3.4.36) and (3.4.37)).

\section{For Case-2:}

In our inventory model, we have considered that the cost parameters $\widetilde{C_{s}}, \widetilde{C_{b}}$, $\widetilde{C_{a}}, \widetilde{C_{c}}$ and $\tilde{p}$ as a triangular fuzzy number. Then the fuzzy numbers are $\widetilde{C_{s}}=$ $\left(C_{s}{ }^{1}, C_{s}{ }^{2}, C_{s}{ }^{3}\right), \widetilde{C_{b}}=\left(C_{b}{ }^{1}, C_{b}{ }^{2}, C_{b}{ }^{3}\right), \widetilde{C_{a}}=\left(C_{a}{ }^{1}, C_{a}{ }^{2}, C_{a}{ }^{3}\right), \widetilde{C_{c}}=\left(C_{c}{ }^{1}, C_{c}{ }^{2}, C_{c}{ }^{3}\right)$ and $\tilde{p}=$ $\left(p^{1}, p^{2}, p^{3}\right)$.

We now form interval numbers for triangular fuzzy parameters with the help of the procedure of the nearest interval approximation of a fuzzy number stated above i.e., $\left[C_{s L}, C_{s R}\right],\left[C_{b L}, C_{b R}\right],\left[C_{a L}, C_{a R}\right],\left[C_{a L}, C_{a R}\right]$ and $\left[p_{L}, p_{R}\right]$ and the total average cost is given by 


$$
\begin{aligned}
& \left.\operatorname{Tac}_{2} \overline{\left(t_{2}\right.}, t_{3}\right)=\frac{1}{\left(a+t_{2}+t_{3}+b\right)}\left[\left(C_{s L}\right)^{1-v}\left(C_{s R}\right)^{v}+k s f^{r} l(a+b)+\left(k \frac{s f^{r}}{\left(p_{L)}{ }^{1-v}\left(p_{R}\right)^{v}\right.}-\frac{s f^{r}}{\left(p_{L)}{ }^{1-v}\left(p_{R}\right)^{v}\right.}-\right.\right. \\
& u)\left(\frac{a^{2}}{2}-\alpha \frac{a^{3}}{3}\right)+\frac{s f^{r}}{\left(p_{L}\right)^{1-v}\left(p_{R}\right)^{v}}\left[\frac{\left(a+t_{2}\right)^{2}}{2}-a t_{2}-\frac{a^{2}}{2}\right]+l \frac{s f^{r}}{\alpha}\left[e^{\alpha t_{2}}-1\right]-l s f^{r} t_{2} \\
& -\left(C_{b L}\right)^{1-v}\left(C_{b R}\right)^{v} \frac{s f^{r}}{\left(p_{L}\right)^{1-v}\left(p_{R}\right)^{v}}\left[\left(a+t_{2}+t_{3}\right) \frac{\left(a+t_{2}-t_{3}\right)}{2}-\frac{\left(a+t_{2}\right)^{2}}{2}\right]- \\
& \left(C_{b L}\right)^{1-v}\left(C_{b R}\right)^{v}\left(k \frac{s f^{r}}{\left(p_{L}\right)^{1-v}\left(p_{R}\right)^{v}}-\frac{s f^{r}}{\left(p_{L}\right)^{1-v}\left(p_{R}\right)^{v}}-u\right)\left[\frac{\left(a+t_{2}+t_{3}+b\right)^{2}}{2}-\left(a+t_{2}+\right.\right. \\
& \left.\left.t_{3}\right) \frac{\left(a+t_{2}+t_{3}+2 b\right)}{2}\right]+\left(C_{a L}\right)^{1-v}\left(C_{a R}\right)^{v} f+l d s f^{r} t_{2}-l I_{e} k s f^{r} a-I_{e} s f^{r}\left(a+t_{2}\right)-I_{e}\left(s f^{r}-\right. \\
& \left.\left.l k s f^{r}\right) b\right]
\end{aligned}
$$

Subject to, $\quad k(a+b) \geq \frac{1}{\alpha}\left[e^{\alpha t_{2}}-1\right]+t_{3}$

$$
\left(C_{c L}\right)^{1-v}\left(C_{c R}\right)^{v} \geq \frac{l s f^{r}}{\alpha}\left[e^{\alpha t_{2}}-1\right]+l s f^{r} t_{3}
$$

Similarly, the necessary condition for the total average cost of the system is minimize if equation (3.4.37) is satisfy the conditions stated above equations (3.4.34) and (3.4.35)under certain sufficient conditions ( i.e. inequalities (3.4.36) and (3.4.37)).

\section{Numerical Solution}

\subsection{Solution in Crisp Environment:}

A manufacturing company produces and sell of items. The necessary information's for the concerned item is given as follows:

\subsubsection{Case-1, Example-1:}

From the past records it is seen that display shelf-space $(s)=35 s q$. inch per unit item, frequency of advertisement $(f)=5$ per cycle, power of advertisement $(r)=3 p e r$ cycle, holding cost exponential parameter $(\alpha)=0.01$ per cycle, selling price $(p)=\$ 25 p e r$ unit of an item, the constant $(k)=1.4$ proportional to demand per unit per cycle defective units $(u)=26$ per cycle. 
the fixed set up cost $\left(C_{s}\right)=\$ 60$ per batch,

the constant $(I)=0.12$ proportional to selling price per unit per cycle,

the storage cost $\left(C_{b}\right)=\$ 0.5$ per unit item,

the advertisement cost $\left(C_{a}\right)=\$ 50$ per advertisement,

the discount $(d)=\$ 0.54$ per unit per cycle.

the interest yielded $\left(l_{p}\right)=0.01 \%$ for unit fund per cycle,

the interest earned $\left(l_{e}\right)=0.02 \%$ for unit fund per cycle,

the delay in payment time $(\mathrm{M})=1.2$ days,

total amount of capital investment $\left(C_{c}\right)=\$ 1000$ per cycle

Using the solution procedure describe above, the result are presented in the following table:

Table 1: Optimal solution of the proposed model in Crisp Environment

\begin{tabular}{|c|c|c|}
\hline$t_{2}^{*}$ & $t_{3}^{*}$ & $\operatorname{Tac}\left(t_{2}, t_{3}\right)^{*}$ \\
\hline 0.9149060 & $0.2994649 \mathrm{E}-01$ & 693.4914 \\
\hline
\end{tabular}

\subsubsection{Case-1, Example-2:}

From the past records it is seen that for any company-

display shelf-space $(s)=0.3$ sq. feet per unit item,

frequency of advertisement $(f)=5$ per cycle,

power of advertisement $(r)=3.5$ per cycle,

holding cost exponential parameter $(\alpha)=0.1$ per cycle,

selling price $(p)=\$ 41$ per unit of an item,

the constant $(\mathrm{k})=1.25$ proportional to demand per unit per cycle,

defective units $(u)=6$ per cycle.

the fixed set up cost $\left(C_{S}\right)=\$ 1250$ per batch,

the constant $(I)=0.4$ proportional to selling price per unit per cycle,

the storage cost $\left(C_{b}\right)=\$ 4$ per unit item, 
the advertisement cost $\left(C_{a}\right)=\$ 150$ per advertisement,

the discount $(\mathrm{d})=\$ 2$ per unit item per cycle,

the interest yielded $\left(l_{p}\right)=0.5 \%$ for unit fund per cycle,

the interest earned $\left(l_{e}\right)=0.4 \%$ for unit fund per cycle,

the delay in payment time $(M)=1.2$ days

Total amount of capital investment $\left(C_{c}\right)=\$ 15000$ per cycle.

Using the solution procedure describe above, the result are presented in the following table:

Table 2: Optimal solution of the proposed model in Crisp Environment

\begin{tabular}{|c|c|c|}
\hline$t_{2}^{*}$ & $t_{3}^{*}$ & $\operatorname{Tac}\left(t_{2}, t_{3}\right)^{*}$ \\
\hline 6.598888 & 0.7749249 & 268.0467 \\
\hline
\end{tabular}

\subsubsection{Case-2, Example -1:}

From the past records it is seen that

display shelf-space (s) = 9 sq. inch per unit item,

frequency of advertisement $(f)=4$ per cycle,

power of advertisement $(r)=3.4$ per cycle,

holding cost exponential parameter $(\alpha)=0.01$ per cycle,

selling price $(p)=\$ 16$ per unit of an item,

the constant $(\mathrm{k})=1.28$ proportional to demand per unit per cycle

defective units $(u)=5$ per cycle.

the fixed set up cost $\left(C_{s}\right)=\$ 50$ per batch,

the constant $(I)=0.3$ proportional to selling price per unit per cycle,

the storage cost $\left(C_{b}\right)=\$ 0.5$ per unit item,

the advertisement cost $\left(C_{a}\right)=\$ 44$ per advertisement,

the discount $(\mathrm{d})=\$ 0.2$ per unit per cycle.

the interest earned $\left(l_{e}\right)=0.023 \%$ for unit fund per cycle, 
INDEPENDENT JOURNAL OF MANAGEMENT \& PRODUCTION (IJM\&P)

http://www.ijmp.jor.br

v. 10, n. 3, May - June 2019

ISSN: 2236-269X

DOI: 10.14807/ijmp.v10i3.865

total amount of capital investment $\left(C_{c}\right)=\$ 750$ per cycle.

Using the solution procedure describe above, the result are presented in the following table:

Table 3: Optimal solution of the proposed model in Crisp Environment

\begin{tabular}{|c|c|c|}
\hline$t_{2}^{*}$ & $t_{3}^{*}$ & $\operatorname{Tac}\left(t_{2}, t_{3}\right)^{*}$ \\
\hline 1.353385 & $0.7308970 \mathrm{E}-01$ & 312.9635 \\
\hline
\end{tabular}

\subsubsection{Case-2, Example - 2:}

From the past records it is seen that

display shelf-space $(s)=0.3$ sq. feet per unit item,

frequency of advertisement $(f)=5$ per cycle,

power of advertisement $(r)=4$ per cycle,

holding cost exponential parameter $(\alpha)=0.01$ per cycle,

selling price $(p)=\$ 65$ per unit of an item,

the constant $(k)=1.3$ proportional to demand per unit per cycle,

defective units $(u)=6$ per cycle,

the fixed set up cost $\left(C_{S}\right)=\$ 525$ per batch,

the constant $(I)=0.2$ proportional to selling price per unit per cycle,

the storage cost $\left(C_{b}\right)=\$ 5$ per unit item,

the advertisement cost $\left(C_{a}\right)=\$ 150$ per advertisement,

the discount $(\mathrm{d})=\$ 0.9$ per unit per cycle,

the interest earned $\left(l_{e}\right)=0.04 \%$ for unit fund per cycle,

total amount of capital investment $\left(C_{c}\right)=\$ 10000$ per cycle.

Using the solution procedure describe above, the result are presented in the following table:

Table 4: Optimal solution of the proposed model in Crisp Environment

\begin{tabular}{|c|c|c|}
\hline$t_{2}^{*}$ & $t_{3}^{*}$ & $\operatorname{Tac}\left(t_{2}, t_{3}\right)^{*}$ \\
\hline 6.865024 & 0.2645908 & 230.4581 \\
\hline
\end{tabular}


INDEPENDENT JOURNAL OF MANAGEMENT \& PRODUCTION (IJM\&P)

http://www.ijmp.jor.br

v. 10, n. 3, May - June 2019

ISSN: 2236-269X

DOI: 10.14807/ijmp.v10i3.865

\subsection{Solution in Fuzzy Environment}

\subsubsection{Case-1, Example-1:}

From the above example in 4.1.1, If we take the input costs, total capital investment and selling price of the proposed inventory model as linear fuzzy number, then the fuzzy numbers are $\widetilde{C_{s}}=(50,60,70), \widetilde{C_{b}}=(0.4,0.5,0.6), \widetilde{C_{a}}=(40,50,60), \widetilde{C_{c}}=$ $(900,1000,1100)$ and $\tilde{p}=(21,25,29)$, where others input values are same as above. Using nearest interval approximation method, we get the corresponding interval numbers and interval-valued functions, as follows:

$$
\begin{aligned}
& C_{s}=[55,65] \Rightarrow \widetilde{C_{s}}=(55)^{1-v}(65)^{v} \in[55,65], \\
& C_{b}=[0.45,0.55] \Rightarrow \widetilde{C_{b}}=(0.45)^{1-v}(0.55)^{v} \in[0.45,0.55], \\
& C_{a}=[45,55] \Rightarrow \widetilde{C_{s}}=(45)^{1-v}(55)^{v} \in[45,55] \\
& C_{c}=[950,1050] \Rightarrow \widetilde{C_{c}}=(950)^{1-v}(1050)^{v} \in[950,1050], \\
& \mathrm{p}=[23,27] \Rightarrow \tilde{p}=(23)^{1-v}(27)^{v} \in[23,27], \text { where } v \in[0,1] .
\end{aligned}
$$

The optimal solution of the fuzzy model by interval-valued parametric geometric programming is presented in Table below:

Table 5: The Optimal Solution for proposed Fuzzy Inventory Model

\begin{tabular}{|c|c|c|c|}
\hline$v$ & $t_{2}^{*}$ & $t_{3}^{*}$ & $\operatorname{Tac}\left(t_{2}, t_{3}\right)^{*}$ \\
\hline 0.0 & 0.8395553 & $0.2952033 \mathrm{E}-01$ & 689.9308 \\
\hline 0.2 & 0.8675971 & $0.2967504 \mathrm{E}-01$ & 691.2982 \\
\hline 0.4 & 0.8965497 & $0.2983279 \mathrm{E}-01$ & 692.6211 \\
\hline $\mathbf{0 . 5}$ & $\mathbf{0 . 9 1 1 3 7 6 2}$ & $\mathbf{0 . 2 9 9 1 2 8 5 E - 0 1}$ & $\mathbf{6 9 3 . 2 6 4 3}$ \\
\hline 0.6 & 0.9264409 & $0.2999371 \mathrm{E}-01$ & 693.8944 \\
\hline 0.8 & 0.9572987 & $0.3015788 \mathrm{E}-01$ & 695.1126 \\
\hline 1.0 & 0.9891514 & $0.3032538 \mathrm{E}-01$ & 696.2696 \\
\hline
\end{tabular}

Here we have given graphs, which shown how change the value of $t_{2}^{*}, t_{3}^{*}$ and $\operatorname{Tac}\left(t_{2}, t_{3}\right)^{*}$ for different values of $v \in[0,1]$. 
INDEPENDENT JOURNAL OF MANAGEMENT \& PRODUCTION (IJM\&P)

http://www.ijmp.jor.br

v. 10, n. 3, May - June 2019

ISSN: 2236-269X

DOI: 10.14807/ijmp.v10i3.865

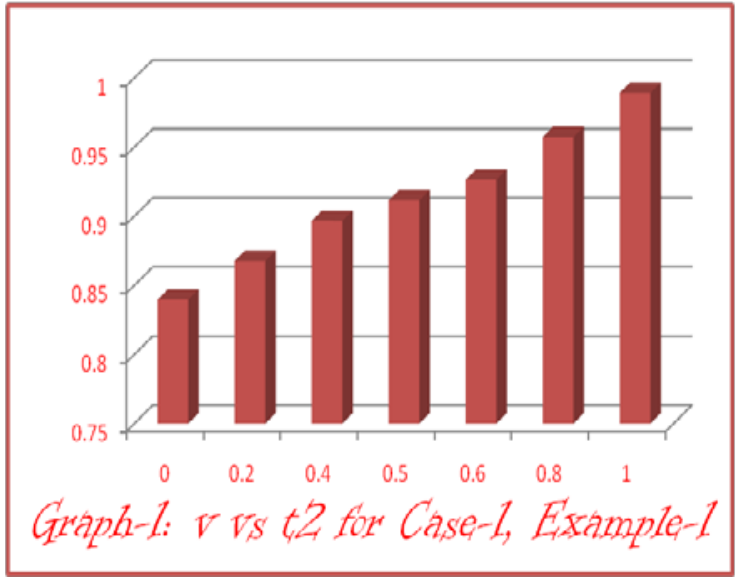

Graph 1:v vs $t_{2}^{*}$ for Case 1, Example 1

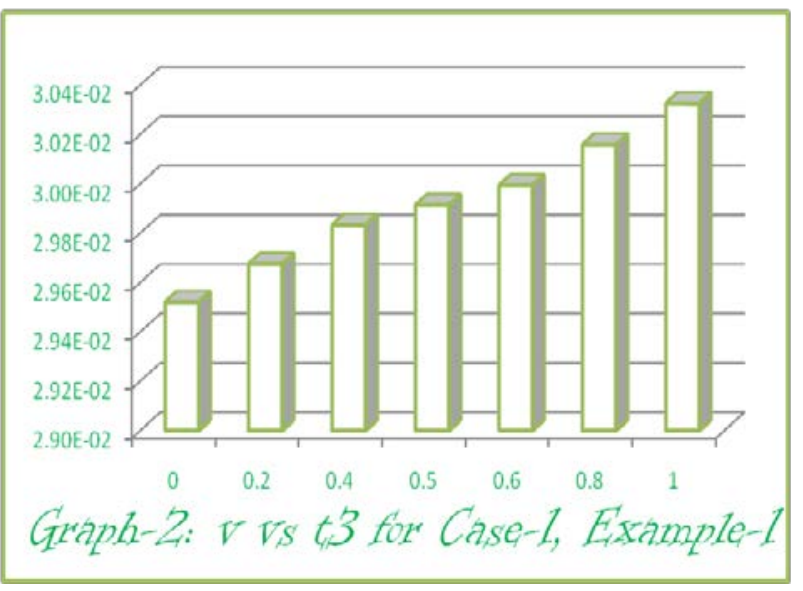

Graph 2: $v$ vs $t_{3}^{*}$ for Case 1, Example 1

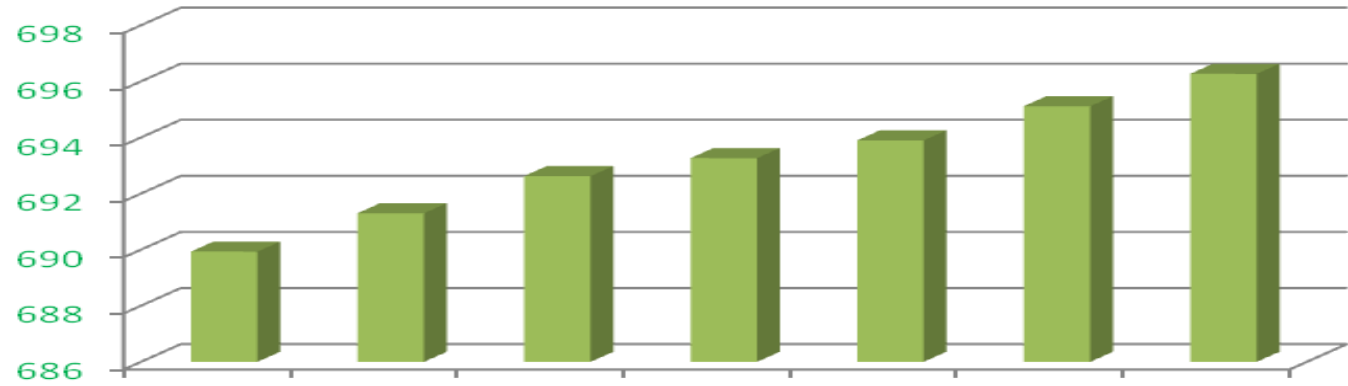

O

0.2

0.4

0.5

0.6

0.8

Graph-3: v vs Tac(t2, t3) for case-1, Example-1

Graphic 3: $v$ vs $\operatorname{Tac}\left(t_{2}, t_{3}\right) *$ for Case 1, Example 1

\subsubsection{Case-1, Example-2:}

From the above example in 4.1.1.2, If we take the input costs', total capital investment and selling price of the proposed inventory model as linear fuzzy number, then the fuzzy numbers are $\widetilde{C_{s}}=(1200,1250,1300), \widetilde{C_{b}}=(3,4,5), \widetilde{C_{a}}=(140,150,160)$, $\widetilde{C_{c}}=(13000,15000,17000)$ and $\tilde{p}=(35,41,47)$ and others input values are same as above. Using nearest interval approximation method, we get the corresponding interval numbers and interval-valued functions, as follows:

$$
\begin{aligned}
& C_{s}=[1225,1275] \Rightarrow \widetilde{C_{s}}=(1225)^{1-v}(1275)^{v} \in[1225,1275], \\
& C_{b}=[3.5,4.5] \Rightarrow \widetilde{C_{b}}=(3.5)^{1-v}(5.5)^{v} \in[3.5,4.5], \\
& C_{a}=[145,155] \Rightarrow \widetilde{C_{s}}=(145)^{1-v}(155)^{v} \in[145,155] \\
& C_{c}=[14000,16000] \Rightarrow \widetilde{C_{c}}=(14000)^{1-v}(16000)^{v} \in[14000,16000], \\
& \mathrm{p}=[38,44] \Rightarrow \tilde{p}=(38)^{1-v}(44)^{v} \in[38,44], \text { where } v \in[0,1] .
\end{aligned}
$$


INDEPENDENT JOURNAL OF MANAGEMENT \& PRODUCTION (IJM\&P)

http://www.ijmp.jor.br

v. 10, n. 3, May - June 2019

ISSN: 2236-269X

DOI: 10.14807/ijmp.v10i3.865

The optimal solution of the fuzzy model by interval-valued parametric geometric programming is presented in Table below:

Table 6: The Optimal Solution for Proposed Fuzzy Inventory Model

\begin{tabular}{|c|c|c|c|}
\hline$v$ & $t_{2}^{*}$ & $t_{3}^{*}$ & $\operatorname{Tac}\left(t_{2}, t_{3}\right)^{*}$ \\
\hline 0.0 & 5.889006 & 0.8388962 & 255.2966 \\
\hline 0.2 & 6.164555 & 0.8146692 & 260.1437 \\
\hline 0.4 & 6.436470 & 0.7907144 & 264.9636 \\
\hline $\mathbf{0 . 5}$ & $\mathbf{6 . 5 7 1 0 3 2}$ & $\mathbf{0 . 7 7 8 8 4 5 6}$ & $\mathbf{2 6 7 . 3 6 1 9}$ \\
\hline 0.6 & 6.681199 & 0.7676471 & 269.7519 \\
\hline 0.8 & 6.620103 & 0.7526445 & 274.5991 \\
\hline 1.0 & 6.559204 & 0.7380194 & 279.5790 \\
\hline
\end{tabular}

Here we have given graphs, which shown how change the value of of $t_{2}^{*}, t_{3}^{*}$ and $\operatorname{Tac}\left(t_{2}, t_{3}\right)^{*}$ for different values of $v \in[0,1]$.

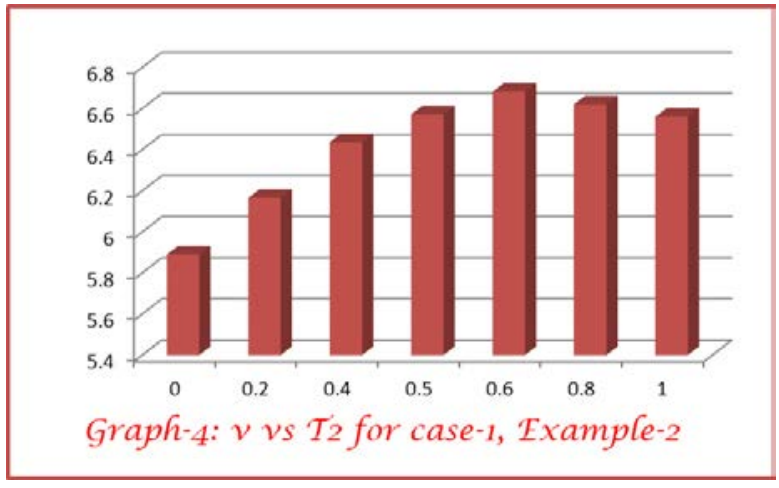

Graph 4: $v$ vs $t_{2}^{*}$ for Case 1, Example 2

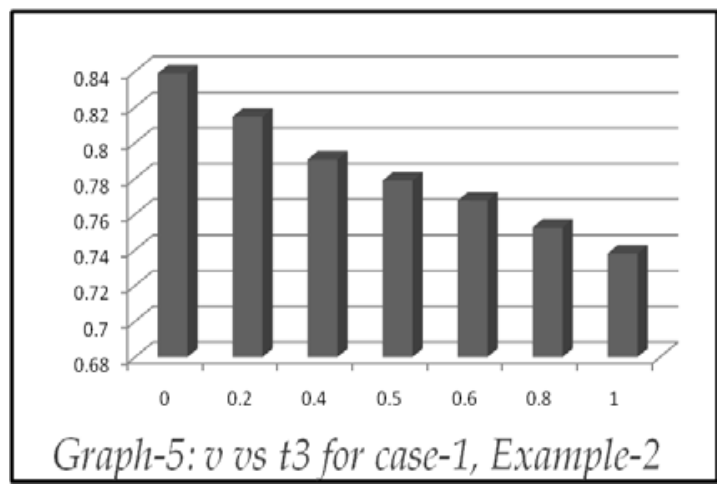

Graph 5: $v$ vs $t_{3}^{*}$ for Case 1, Example 2

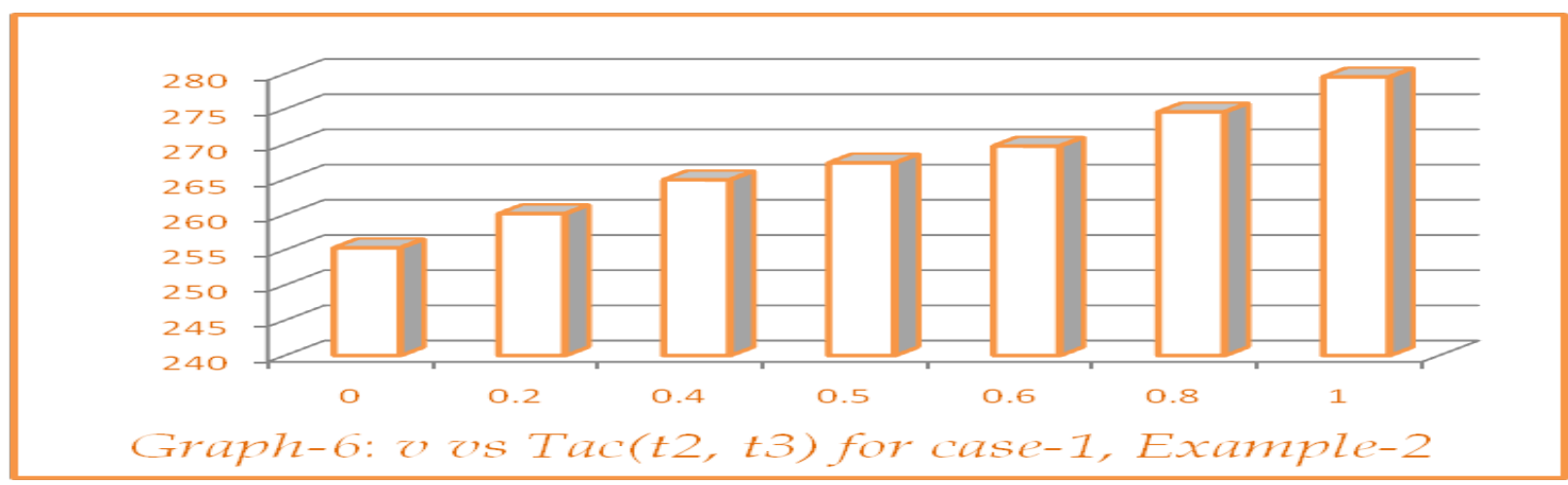

Graph 6: $v$ vs Tac $\left(t_{2}, t_{3}\right){ }^{*}$ for Case 1, Example 2

\subsubsection{Case-2, Example-1:}

From the above example in 4.1.2.1, if we take the input data's of the proposed inventory model as linear fuzzy number, then the fuzzy numbers are $\widetilde{C_{s}}=(40,50,60)$, $\widetilde{C_{b}}=(0.48,0.50,0.52), \widetilde{C_{a}}=(34,44,54), \widetilde{C_{c}}=(650,750,850)$ and $\tilde{p}=(10,16,22)$, where others input values are same as above. Using nearest interval approximation method, we get the corresponding interval numbers and interval-valued functions, as follows: 
INDEPENDENT JOURNAL OF MANAGEMENT \& PRODUCTION (IJM\&P)

http://www.ijmp.jor.br

v. 10, n. 3, May - June 2019

ISSN: 2236-269X

DOI: 10.14807/ijmp.v10i3.865

$$
\begin{aligned}
& C_{s}=[45,55] \Rightarrow \widetilde{C_{s}}=(45)^{1-v}(55)^{v} \in[45,55], \\
& C_{b}=[0.49,0.51] \Rightarrow \widetilde{C_{b}}=(0.49)^{1-v}(0.51)^{v} \in[0.49,0.51], \\
& C_{a}=[39,49] \Rightarrow \widetilde{C_{s}}=(39)^{1-v}(49)^{v} \in[39,49], \\
& C_{c}=[700,800] \Rightarrow \widetilde{C_{c}}=(700)^{1-v}(800)^{v} \in[700,800], \\
& \mathrm{p}=[13,19] \Rightarrow \tilde{p}=(13)^{1-v}(19)^{v} \in[13,19], \text { where } v \in[0,1] .
\end{aligned}
$$

The optimal solution of the fuzzy model by interval-valued parametric geometric programmingis presented in Table below:

Table 7: The Optimal Solution for Proposed Fuzzy Inventory Model

\begin{tabular}{|c|c|c|c|}
\hline$v$ & $t_{2}^{*}$ & $t_{3}^{*}$ & $\operatorname{Tac}\left(t_{2}, t_{3}\right)^{*}$ \\
\hline 0.0 & 1.145517 & $0.7339285 \mathrm{E}-01$ & 324.5610 \\
\hline 0.2 & 1.214499 & $0.7258219 \mathrm{E}-01$ & 321.8566 \\
\hline 0.4 & 1.287479 & $0.7179232 \mathrm{E}-01$ & 319.0499 \\
\hline 0.5 & 1.325557 & $0.7140683 \mathrm{E}-01$ & 317.6020 \\
\hline $\mathbf{0 . 6}$ & $\mathbf{1 . 3 6 4 7 5 0}$ & $\mathbf{0 . 7 1 0 2 8 7 8 E - 0 1}$ & $\mathbf{3 1 6 . 1 2 0 4}$ \\
\hline 0.8 & 1.446687 & $0.7029944 \mathrm{E}-01$ & 313.0398 \\
\hline 1.0 & 1.533798 & $0.6961592 \mathrm{E}-01$ & 309.7684 \\
\hline
\end{tabular}

Here we have given graphs, which shown how change the value of $t_{2}^{*}, t_{3}^{*}$ and $\operatorname{Tac}\left(t_{2}, t_{3}\right)^{*}$ for different values of $v \in[0,1]$.

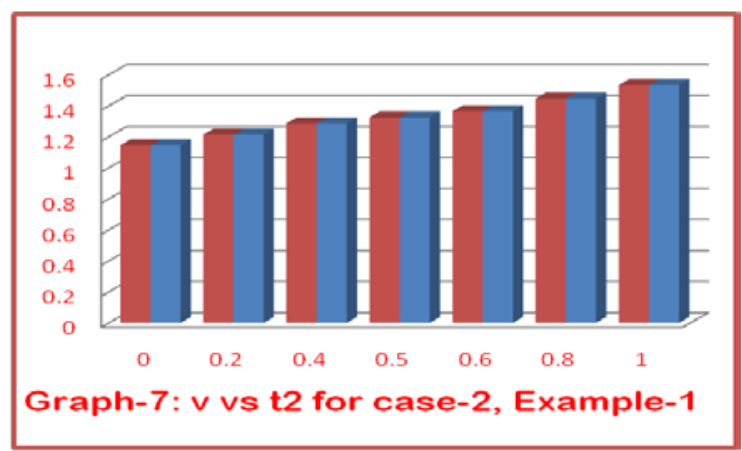

Graph 7: $v$ vs $t_{2}^{*}$ for Case 2, Example 1

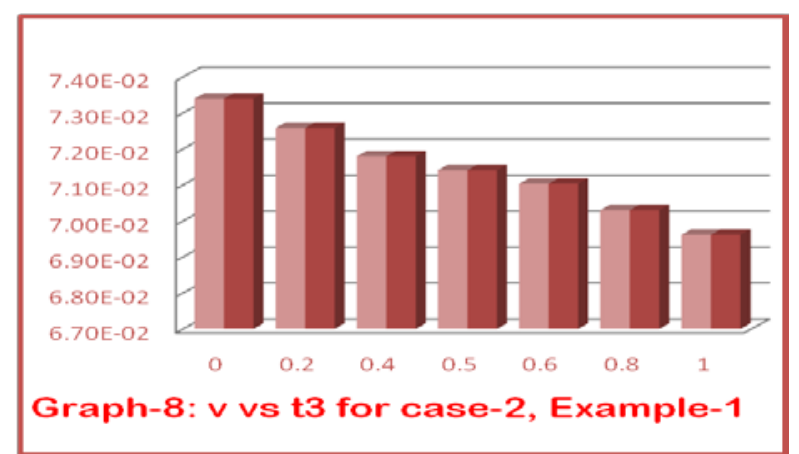

Graph 8: $v$ vs $t_{3}^{*}$ for Case 2, Example 1

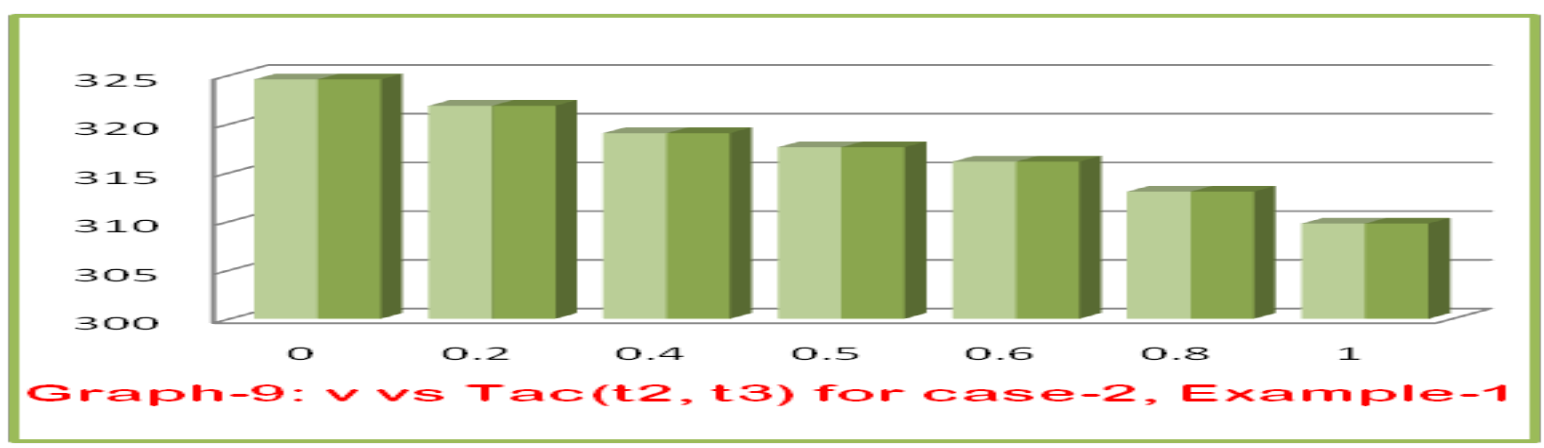

Graph 9: $v$ vs Tac $\left(t_{2}, t_{3}\right)^{*}$ for Case 2, Example 1

\subsubsection{Case-2, Example-2:}


INDEPENDENT JOURNAL OF MANAGEMENT \& PRODUCTION (IJM\&P)

http://www.ijmp.jor.br

v. 10, n. 3, May - June 2019

ISSN: 2236-269X

DOI: 10.14807/ijmp.v10i3.865

From the above example in 4.1.2.2, if we take the input data's of the proposed inventory model as linear fuzzy number, then the fuzzy numbers are $\widetilde{C_{S}}=$ $(505,525,545), \widetilde{C_{b}}=(3,5,7), \widetilde{C_{a}}=(130,150,170), \widetilde{C_{c}}=(8000,1000,12000)$ and $\tilde{p}=$ $(55,65,75)$, where others input values are same as above. Using nearest interval approximation method, we get the corresponding interval numbers and interval-valued functions, as follows:

$$
\begin{aligned}
& C_{s}=[515,535] \Rightarrow \widetilde{C_{s}}=(515)^{1-v}(535)^{v} \in[515,535], \\
& C_{b}=[4,6] \Rightarrow \widetilde{C_{b}}=(4)^{1-v}(6)^{v} \in[4,6], \\
& C_{a}=[140,160] \Rightarrow \widetilde{C_{s}}=(140)^{1-v}(160)^{v} \in[140,160], \\
& C_{c}=[9000,11000] \Rightarrow \widetilde{C_{c}}=(9000)^{1-v}(11000)^{v} \in[9000,11000], \\
& \mathrm{p}=[60,70] \Rightarrow \tilde{p}=(60)^{1-v}(70)^{v} \in[60,70], \text { where } v \in[0,1] .
\end{aligned}
$$

The optimal solution of the fuzzy model by interval-valued parametric geometric programming is presented in Table below.

Table 8: The Optimal Solution for proposed Fuzzy Inventory Model

\begin{tabular}{|c|c|c|c|}
\hline$v$ & $t_{2}^{*}$ & $t_{3}^{*}$ & $\operatorname{Tac}\left(t_{2}, t_{3}\right)^{*}$ \\
\hline 0.0 & 7.503546 & 0.2857741 & 210.3772 \\
\hline 0.2 & 7.377425 & 0.2778402 & 216.7752 \\
\hline 0.4 & 7.252474 & 0.2701511 & 223.4587 \\
\hline 0.5 & 7.190394 & 0.2663937 & 226.9127 \\
\hline 0.6 & $\mathbf{7 . 1 2 8 5 5 7}$ & $\mathbf{0 . 2 6 2 6 9 2 2}$ & $\mathbf{2 3 0 . 4 4 4 6}$ \\
\hline 0.8 & 7.005571 & 0.2554510 & 237.7505 \\
\hline 1.0 & 6.883443 & 0.2484168 & 245.3949 \\
\hline
\end{tabular}

Here we have given a rough sketch, which shown how change the value of $t_{2}^{*}$, $t_{3}^{*}$ and $\operatorname{Tac}\left(t_{2}, t_{3}\right)^{*}$ for different values of $v \in[0,1]$.

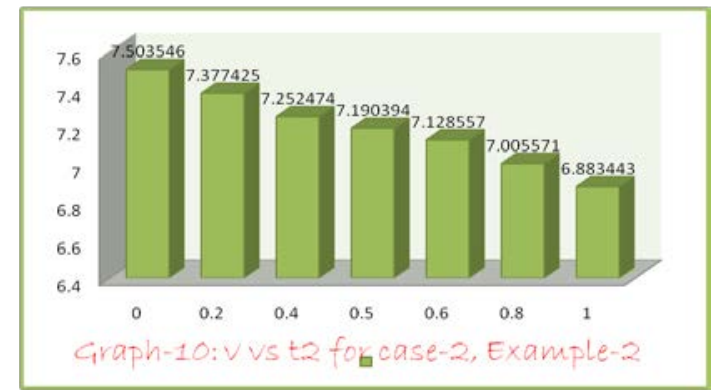

Graph 10:v vs $t_{2}^{*}$ for Case 2, Example 2

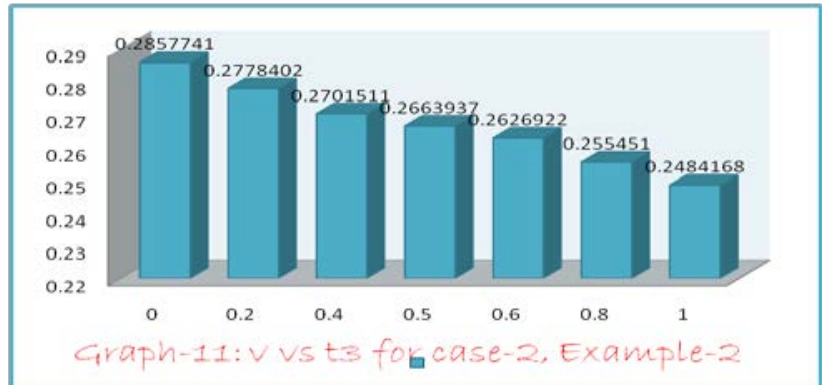

Graph 11: $v$ vs $t_{3}^{*}$ for Case 2, Example 2 


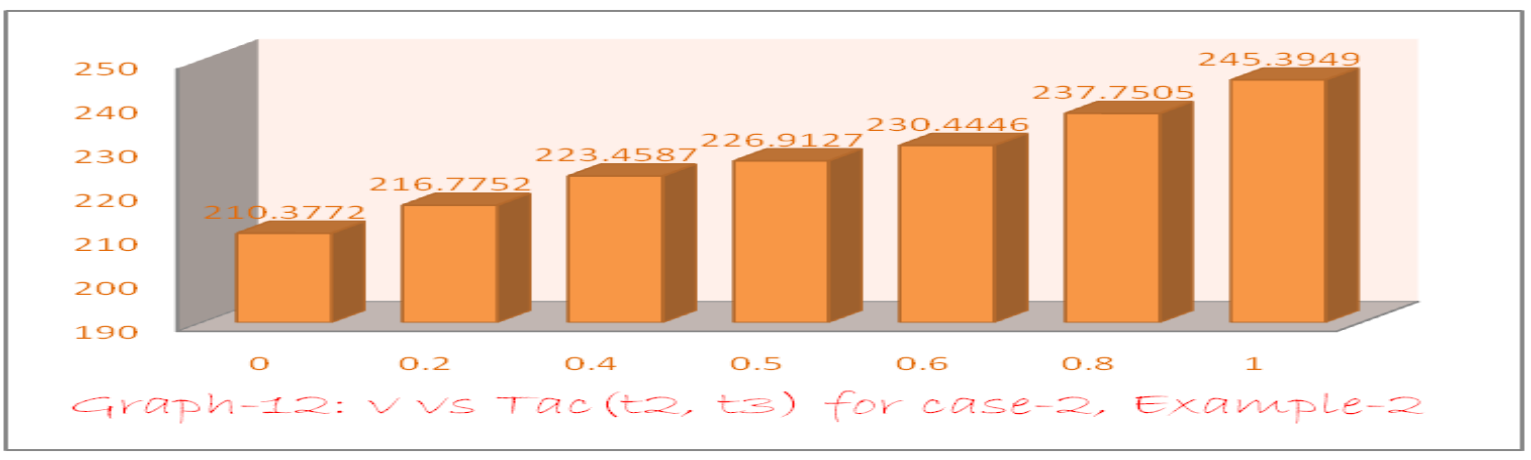

Graph 12: $v$ vs Tac $\left(t_{2}, t_{3}\right)^{*}$ for Case 2, Example 2

\section{Observations}

Here, we have taken the possible values of Cost parameter, selling price and display shelf-space in the parametric interval form as $\left[a_{L}, a_{R}\right]$, where $a_{L}$ be the lower limit and $a_{R}$ be the upper limit of the interval numbers.Now, comparing the result obtained from Case-1, Example-1 and Case-1, Example-2 in Crisp Environment with the result received from Case-1, Example-1and Case-1, Example-2 in fuzzy environment respectively, we observed that when power of the lower limit is equal to 0.5 , i.e. power of the upper limit is equal to 0.5 , then two results are almost the same. On the other hand, comparing the result obtained from Case-2, Example-1 and Case2, Example-2 in Crisp Environment with the result received from Case-2, Example1and Case-2, Example-2 in fuzzy environment respectively, we observed that when power of the lower limit is equal to 0.6, i.e. power of the upper limit is equal to 0.4 , then two results are almost the same. A decision maker may get the ideal outcomes as per his desire utilizing the result of this model.

\section{Conclusions}

In this paper, we produced a real-life E. P. Q. Inventory Model in a crisp environment. The inventory model developed for selling price, display shelf-space and frequency of advertisement depended on demand with time depended holding cost and fully backlogged shortages under non-instantaneous deterioration. Here, delay in payment is permissible. In this model, also, production is proportional to demand and demand rate is taken as $D(s, f, p)=\frac{s f^{r}}{p}$. From this assumption, we may say, lesser 
advertisement and display shelf-space lesser demand for fixed value of $r$ and lesser selling price greater demand.

Here, the crisp model has produced then it changed to fuzzy model taking the linear fuzzy number for the Cost parameters, selling price and display shelf-space and illuminated by the nearest interval approximation method, thereafter transformed this interval number to a parametric interval-valued functional form and solved. This model has been developed for the single item.

This type of inventory model is a potential field of research. In the future, a lot of scope for additional work based on what has been presented in this research work. On the other side, in the fuzzy environment, the other sort of membership functions such as piecewise linear hyperbolic Fuzzy Number, Parabolic Fuzzy Number (pFN), Parabolic flat Fuzzy Number (PfFN), Piecewise Linear Hyperbolic Fuzzy Number, Parabolic level Fuzzy Number (PfFN), Pentagonal Fuzzy number and so forth can be considered to construct the membership function and then the model can be easily solved by using Werner's Approach, Geometric Programming (GP) technique, Nearest Symmetric Triangular Defuzzification (NSTD) method and so forth.

\section{Acknowledgement}

The authors are thankful to University of Kalyani for providing financial assistance through DST-PURSE Programme. The authors would like to thank the editor and anonymous reviewers for their valuable and constructive comments and suggestions which have led to a significant improvement in the manuscript.

\section{REFERENCES}

BELLMANN, R. E.; ZADEH, L. A. (1970 ) Decision Making in a Fuzzy Environment, Management Science, v. 17, n. 4.

CARLSSON, C.; KORHONEN, P. (1986) A parametric approach to fuzzy linear programming, Fuzzy sets and systems, p. 17-30. DOI: 10.1016/S01650114(86)80028-8.

DUBOIS, D.; PRADE, H. (1978) Operation on fuzzy numbers, International Journal of SystemsScience, v. 9, n. 6, p. 613-626.

GHARE, P. M.; SCHRADER, G. H. (1963) A model for exponentially decaying inventory system, International Journal of Production Research, v. 21, p. 449460. 
GRZEGORZEWSKI, P. (2002) Nearest interval approximation of a fuzzy number, Fuzzy Sets and Systems, n. 130, p. 321-330.

LADANY, S.; STERNLEIB, A. (1974) The intersection of economic ordering quantities and marketing policies, AllE Transactions, v. 6, p. 173-175.

MONDAL, W. A.; ISLAM, S. (2016) Fuzzy EOQ Model For Deteriorating Items, With Constant Demand, Shortages and Fully Backlogging, Oxford Journal of Intelligent Decision and Data Science, ISSN: 2366-9934, v. 2016, n. 2, p 29-45.

MONDAL, N. K.; ROY, T. K. (2006) A displayed inventory model with L-R fuzzy number, Fuzzy OptimDecis Making, v. 5, p. 227-243, DOI: 10.1007/s10700-0060012-1.

OU, S. M. (2016) An optimal replenishment policy under Conditions of permissible delay in payment, International Journal of Engineering and Applied Sciences (IJEAS), ISSN: 2394-3661, v. 3, n. 10.

OUYANG, L. Y.; WU, K. S.; YANG, C. T. (2006) A study on an inventory model for non-instantaneous deteriorating items with permissible delay in payments,

Computers and Industrial Engineering, v. 51, p. 637-651.

SUBRAMANYAM, S.; KUMARASWAMY, S. (1981) EOQ formula under varying marketing policies and conditions, AllE Transactions, v. 13, n. 4, p. 312-314.

URBAN, T. L. (1992) Deterministic inventory models incorporating marketing decisions, Computers \& Industrial Engineering, v. 22, p. 5-93.

WEE, H. M. (1999) Deteriorating inventory model with quantity discount, pricing and partial backordering, International Journal of Production Economics, 59, 511- 518.

WHITIN, T. N. (1957) The theory of inventory management. Princeton, NJ: Princeton University Press.

ZADEH, L. A. (1965) Fuzzy sets, Information and Control, v. 8, n. 3, p. 338-353.

ZIMMERMAN, H. J. (1985) Application of fuzzy set theory to mathematical programming, Information Science, v. 36, p. 29-58. 